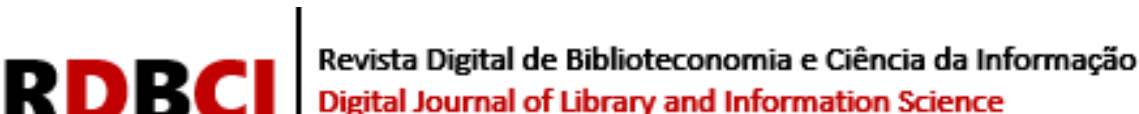 \\ Digital Journal of Library and Information Science
}

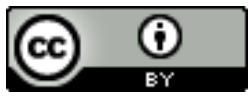

\section{Análise bibliométrica dos artigos científicos de jurimetria publicados no Brasil}

\author{
Marcos Maia ${ }^{1}$ iD https://orcid.org/0000-0003-3937-5224 \\ Cicero Aparecido Bezerra ${ }^{2}$ iD https://orcid.org/0000-0001-5027-9394 \\ ${ }^{1}$ Universidade Federal do Paraná, Curitiba, PR, Brasil / e-mail: maia.marcosmaia@gmail.com \\ ${ }^{2}$ Universidade Federal do Paraná, Curitiba, PR, Brasil / e-mail: cicero.bezerra@ufpr.br
}

\section{RESUMO}

A morosidade judicial tem sido tema de debates na comunidade acadêmica brasileira. Entre as soluções discutidas, a jurimetria tem ganhado espaço ao buscar por padrões quantitativos nas decisões judiciais. Porém, em que pese a relevância desta metodologia, no Brasil, poucas pesquisas têm sido conduzidas no sentido de sua disseminação. Assim sendo, o presente estudo emprega técnicas de bibliometria sobre a produção científica nacional, artigos, relacionada ao termo "jurimetria", de 2002 até 2019, disponibilizada na ferramenta de pesquisa do Google Acadêmico, apresentando um painel informativo sobre as características encontradas nestas publicações. Os resultados mostram que no período pesquisado, o número de publicações sobre o tema apresentou um crescimento médio anual de 18,92\%; o índice de colaboração indica que existem, em média, 2,32 autores por artigo, sendo que alguns se destacam pelo número de publicações, entre eles, Daniel F. N. Menezes (quatro) e Filipe J. Zabala (três) e, por sua vez, os autores mais citados são Lee Loevinger (onze citações), Filipe J. Zabala e Fabiano F. Silveira (ambos com seis citações); já a revista que mais tem publicado sobre o tema é a Revista da Faculdade de Direito da Universidade Federal de Minas Gerais, sendo que uma única revista publicou quatro artigos, sete revistas dois artigos e 66 revistas um único artigo e, finalmente; quanto às palavras-chaves associadas ao termo, destacam-se as palavras: "adoção", "processo civil”, "ato inválido", "ato ilícito", "dissolução parcial”, e, "incidência sucessiva", sugerindo o Direito Civil como uma área do direito mais alinhada ao uso da jurimetria.

\section{PALAVRAS-CHAVE}

Produção científica jurídica. Estudos jurídicos empíricos. Indicadores bibliométricos.

$$
\begin{gathered}
\text { Bibliometric analysis of scientific articles } \\
\text { on jurimetry published in Brazil }
\end{gathered}
$$

\footnotetext{
ABSTRACT

Judicial delays have been the subject of debate in the Brazilian academic community. Among the solutions discussed, jurimetrics has gained ground in seeking quantitative standards in court decisions. However, despite the relevance of this methodology, in Brazil, few researches have been conducted towards its dissemination. Therefore, the present study employs bibliometric techniques on national scientific production, articles, related to the term "jurimetry", from 2002 to 2019, made available on the Google Scholar search tool, presenting an information panel on the characteristics found in these publications. The results show that in the period surveyed, the number of publications on the subject showed an average annual growth of $18.92 \%$; the collaboration index indicates that there are, on average, 2.32 authors per article, some of which stand out for the number of publications, including Daniel F. N. Menezes (four) and Filipe J. Zabala (three) and, in turn, , the most cited authors are Lee Loevinger (eleven citations), Filipe J. Zabala and Fabiano F. Silveira (both with six citations); the magazine that has published the most on the subject is the Revista da Faculdade de Direito of the Federal University of Minas Gerais, with a single magazine publishing four articles, seven magazines two articles and 66
} 


\section{RDBCI|}

magazines a single article and finally; as for the keywords associated with the term, the words "adoption", "civil procedure", "invalid act", "illegal act", "partial dissolution", and "successive incidence" stand out, suggesting Civil Law as an area of law more aligned to the use of jurimetry.

\section{KEYWORDS}

Legal scientific production. Empirical legal studies. Bibliometric indicators.

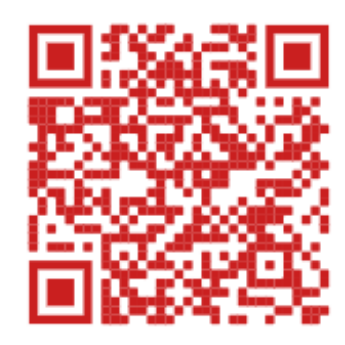

JITA: BB. Bibliometric methods. 


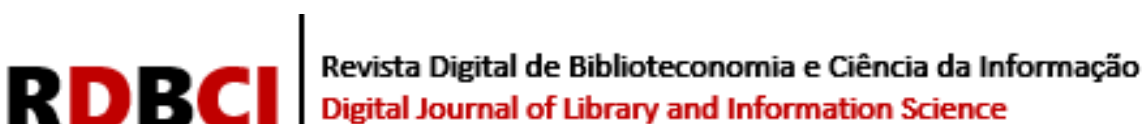

\section{INTRODUÇÃO}

A morosidade judicial afeta significativamente a eficiência do poder judiciário brasileiro (BRITTO, LACERDA e KARNINKE, 2018; GARGANO e NADER, 2018; VENTURINI, SOUZA e BIANCHI, 2018). Esta situação "passou a integrar o cotidiano de discussões da comunidade acadêmica, que se viu obrigada a buscar soluções para tal problema gerador de grande insatisfação social" (BASSI e SCHUMAK, 2018, p. 720). Neste cenário a jurimetria se insere como uma abordagem com real potencial para, no mínimo, sugerir direções capazes de otimizar o tempo razoável para a solução das contendas judiciais (COUTO e OLIVEIRA, 2016). Esta abordagem, segundo Menezes e Barros (2017), é capaz de verificar o impacto da aplicação da lei na sociedade, permitindo avaliar a eficácia de políticas públicas e decisões judiciais, mostrando-se, portanto, inovadora em relação ao paradigma clássico do conhecimento científico.

Embora haja um crescente interesse no estudo da jurimetria no Brasil, constatam-se poucas obras científicas relevantes (ZABALA e SILVEIRA, 2014). Neste mesmo sentido, para Menezes e Barros (2017, p. 80) "inegável é a valia da jurimetria, metodologia ainda pouco explorada, para avaliação do real impacto social da norma ao ser aplicada ao caso concreto".

Assim sendo, dada a importância do tema, este estudo busca contribuir para mitigar a escassez de estudos e contribuir com esta área ao responder o seguinte problema de pesquisa: quais são as características das publicações científicas de jurimetria em língua portuguesa encontradas na ferramenta de pesquisa do Google Acadêmico, até agosto de 2019? Trata-se de um estudo bibliométrico, exploratório, que forma um cenário a partir dos autores com maior número de publicações envolvendo o temo "jurimetria", revistas com maior incidência do termo, palavras-chave mais associadas e os artigos mais citados.

Este artigo, além desta introdução, está organizado em mais quatro seções: o referencial teórico apresenta o conceito de jurimetria, os principais estudos da área e as leis bibliométricas mais utilizadas; os procedimentos metodológicos trazem a definição do corpus de análise, variáveis a serem analisadas e procedimentos analíticos utilizados; a quarta seção é a apresentação e análise dos resultados e, por fim; nas considerações finais são apresentadas as conclusões do estudo, suas limitações e sugestões para pesquisas futuras.

\section{REFERENCIAL TEÓRICO}

Esta seção apresenta os conceitos básicos empregados no presente estudo, não com a intenção de esgotar tais assuntos, mas sim de conduzir ao entendimento das mesmas.

\subsection{Jurimetria: aspectos conceituais e aplicações}

Embora haja divergência na literatura em relação à origem da associação de análises estatísticas ao estudo do Direito, é consenso que esta utilização é muito antiga (ANDRADE, 2018; MACHADO, 2017; NUNES, 2016). Segundo Hald (2003), o termo foi encontrado na tese Dissertatio inauguralis mathematico-juridica (BERNOULLI, 2012), defendida por Nicolou I Bernoulli em 1709. Para Rangel (2014), foi com a publicação do livro The path of the law, do juiz da Suprema Corte dos Estados Unidos, Oliver Wendell Holmes Jr. que se deu notoriedade ao uso da estatística no Direito, com a frase "For the rational study of the law the blackletter man may be the man of the present, but the man of the future is the man of statistics 


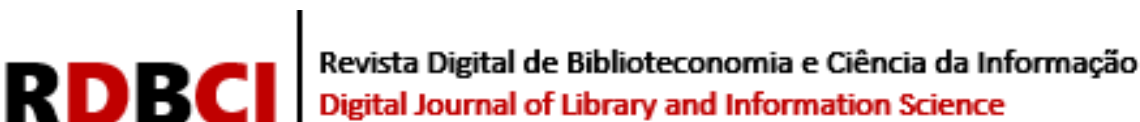

and the master of economics" (HOLMES JR, 1897, p. 457).

Segundo Couto e Oliveira (2016), o termo "jurimetria", neologismo criado pelo advogado norte-americano Lee Loevinger, foi empregado pela primeira vez com a publicação do artigo Jurimetrics: the next step forward (LOEVINGER, 1971), em um contexto no qual a aplicação de métodos analíticos pode trazer progresso e segurança jurídica. Nos Estados Unidos há várias escolas de Direito e associações que possuem centros de pesquisa em jurimetria, tendo como referências a Society for Empirical Legal Studies e o Journal of Empirical Legal Studies (MACHADO, 2017). Já no Brasil, segundo Nunes (2016), este termo começou a ser difundido a partir de 1973, com as palestras do professor italiano Mario Losano. A partir de então, no Brasil, surgiram estudos que passaram a abordar o termo "jurimetria": em 2002, a tese de doutorado de Fernando Antônio de Vasconcelos (2002) sob o título: "Responsabilidade do provedor pelos danos praticados na Internet" e o artigo de José Augusto Delgado (2002), "O direito informático"; em 2003, a tese de doutorado de Alexandre Freire Pimentel (2003), "Principiologia juscibernética. Processo telemático. Uma nova teoria geral do processo e do direito processual civil" e a dissertação de mestrado de Ulysses Alves de Levy Machado (2003), "A convergência entre o privilégio de exploração da criação intelectual e a elaboração de um direito do espaço virtual com suas consequências sobre o domínio público." em 2006, a dissertação de mestrado de Maria Paula Costa Bertran sob o título: "Análise econômica como critério orientador de decisão judicial: aplicações e limites, estudo a partir do caso de revisão dos contratos de arrendamento mercantil com paridade cambial" (BERTRAN, 2006). Nos Estados Unidos há várias escolas de Direito e associações que possuem centros de pesquisa em jurimetria, tendo como referências a Society for Empirical Legal Studies e o Journal of Empirical Legal Studies (MACHADO, 2017).

Para Loevinger (1963), a jurimetria envolve utilização de análise quantitativa, aplicação da teoria da comunicação e da informação às leis, uso da lógica matemática em direito, recuperação de dados legais por meios eletrônicos e mecânicos e a formulação de cálculos almejando a previsibilidade jurídica. Tal conceito é corroborado por Zabala e Silveira (2014, p. 75-76), onde para os quais, "as definições de Jurimetria variam de autor para autor, passando por tópicos como Estatística, Computação, Linguística, Comportamento Humano e Ciência em sua forma mais geral".

Nunes (2016, p. 115-116) descreve o termo jurimetria quanto ao seu objeto e metodologia, o caracterizando como a "investigação do funcionamento da ordem jurídica", cuja metodologia é utilizar a "estatística para restabelecer um elemento de causalidade e investigar os múltiplos fatores (sociais, econômicos, geográficos, éticos, etc.) que influenciam o comportamento dos agentes jurídicos". Para Couto e Oliveira (2016, p. 779), a jurimetria,

\begin{abstract}
busca descrever os interesses concretos dos agentes jurídicos, seus conflitos e as soluções proferidas pelos julgadores, com o intuito de auxiliar o Direito a entender melhor os anseios dos cidadãos e oferecer às autoridades subsídios para uma produção de leis mais consentâneas com a realidade social, assim como, funcionar como ferramenta fundamental para o desenvolvimento das instituições jurídicas mais justas, capazes de assimilar a natureza viva do direito e prestar à sociedade uma tutela jurisdicional célere e pacificadora, ou, alternativamente, apontar os meios não jurisdicionais de solução de controvérsias mais adequados para cada caso (mediação, arbitragem etc.).
\end{abstract}

Neste sentido, para Andrade (2018, p. 687),

\footnotetext{
A jurimetria fornece uma perspectiva sistemática dos fatores que influenciam ou que exercem algum papel na tomada de decisões pelo magistrado, na medida em que contribui para definir, com suporte em elementos quantitativos, padrões de comportamento legal.
} 


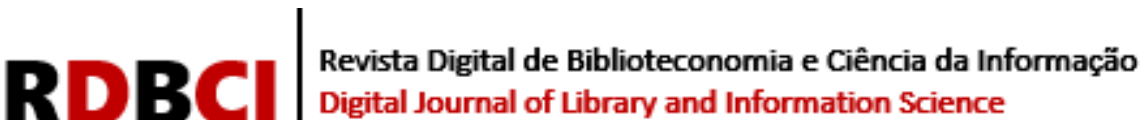

Para Menezes e Barros (2017, p. 56) "inúmeras são as vantagens decorrentes da aplicação da metodologia própria da jurimetria em todas as esferas públicas”. As principais vantagens seriam

a implementação de políticas de transparência, de fiscalização, de eficiência, de redução de gastos, de colheita de dados em tempo real e, principalmente, de análise da realidade social, o que permitiria avaliação da eficácia de políticas públicas, decisões judiciais e leis vigentes ao analisar os correspondentes impactos na sociedade.

Couto e Oliveira (2016) apresentam como aspecto positivo da utilização de técnicas estatísticas, o auxílio na identificação de problemas e o direcionamento das estratégias para equacionamento das dificuldades da gestão do conhecimento. Como desvantagens colocam a dificuldade na obtenção de dados, o conservadorismo e o engessamento do Poder Judiciário. Além disso, segundo Menezes e Barros (2017, p. 57) há que se enfrentarem os seguintes desafios:
a) a dificuldade na compreensão da linguagem estatística pelo jurista (o qual, em regra, não está com ela familiarizado);
b) a interdisciplinariedade a ser observada para a consecução desse estudo;
c) a mudança de hábito representada pela substituição da pesquisa meramente bibliográfica pelo empirismo;
d) o controle de incertezas que é próprio da estatística não o é para o direito.

Embora tenha se elencado a dificuldade na compreensão da linguagem estatística, Machado (2017) relata a existência do mito de que o uso da jurimetria se faz por intermédio de métodos extremamente sofisticados e com uso da matemática e recursos computacionais de ponta, limitando sua aplicação a apenas doutores em Ciências Exatas. Para estes autores, um trabalho jurimétrico é qualquer estudo com objeto pertencente ao mundo jurídico, que tenha a presença de dados coletados empiricamente e cuja análise se baseie de algum conceito estatístico. Ademais, há que se observar que a escolha do método estatístico a ser utilizado não se dá aleatoriamente, mas de acordo com o que se pretende identificar com a pesquisa, mantendo sempre o cuidado de preservar a representatividade da população em casos de generalização dos resultados. Como exemplo de alguns métodos utilizados tem-se o estudo de caso, as estatísticas descritivas e/ou correlações, as regressões de causalidade e outra infinidade de teorias, técnicas e modelos empíricos.

Contudo, Couto e Oliveira (2016) alertam para que se tenha cuidado no emprego direto de ferramentas matemáticas, uma vez que a busca incessante por uma celeridade processual poderia resultar numa prestação jurisdicional massificada e insatisfatória para o sistema judiciário. Isto porque a jurimetria teria a função de diagnosticar problemas e sugerir medidas para a gestão do conhecimento.

Machado (2017) apresenta alguns temas estudados com o uso da jurimetria, sendo os efeitos de: (a) ideologia nas decisões judiciais; (b) gênero nas decisões judiciais; (c) composição e votação em painéis e efeitos de pares e; (d) pressão externa da mídia ou opinião popular sobre decisões judiciais. "Além do gênero, há outros fatores que afetam as decisões judiciais, relacionados a grupos minoritários como raça, etnia, grupo religioso e formação social, dentre outros" (MACHADO, 2017, p. 262). Um resumo dos autores que estudam estes temas são apresentados no Quadro 1:

Quadro 1. Estudos relacionados à jurimetria

\begin{tabular}{|l|l|l|}
\hline Tema & Autores & Objeto de estudo \\
\hline Ideologia & Pritchett (1968) & $\begin{array}{l}\text { Analisa os julgamentos da Suprema Corte Norte } \\
\text { Americana a fim de se identificar padrões } \\
\text { oriundos de diferenças ideológicas. }\end{array}$ \\
\cline { 2 - 3 } & Epstein, Landes e Posner (2013) & Argumentam que os impactos da ideologia \\
\hline
\end{tabular}




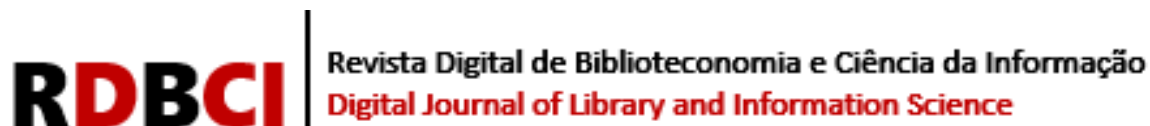

\begin{tabular}{|c|c|c|}
\hline \multirow[t]{4}{*}{ Tema } & Autores & Objeto de estudo \\
\hline & & política vêm crescendo ao longo do tempo. \\
\hline & $\begin{array}{l}\text { Arida, Bacha e Lara-Resende } \\
\text { (2005) }\end{array}$ & $\begin{array}{l}\text { Apontam para a existência de um suposto viés } \\
\text { pró-devedor pelo Judiciário brasileiro. }\end{array}$ \\
\hline & Yeung e Azevedo (2015) & $\begin{array}{l}\text { Analisam os } \begin{array}{l}\text { estudos de } \\
\text { Lara-Resende } \\
(2005)\end{array} \text { em aproxida, Bacha e } \\
1.700 \text { decisões do STJ (Superior Tribunal de } \\
\text { Justiça. }\end{array}$ \\
\hline \multirow[t]{5}{*}{ Gênero } & Peresie (2005) & $\begin{array}{l}\text { Mostra que o gênero dos juízes é determinante } \\
\text { significativo nas decisões dos tribunais de } \\
\text { apelação nos Estados Unidos, em casos de } \\
\text { disputas por assédio e discriminação sexuais. }\end{array}$ \\
\hline & Farhang e Wawro (2004) & $\begin{array}{l}\text { Segundo estes autores, as juízas tendem a } \\
\text { influenciar seus colegas masculinos de maneira } \\
\text { significativa. }\end{array}$ \\
\hline & Boyd, Epstein e Martin (2010) & $\begin{array}{l}\text { Encontram impacto significativo de gênero em } \\
\text { litígios de discriminação sexual. }\end{array}$ \\
\hline & King e Greening (2007) & $\begin{array}{l}\text { Analisaram as decisões do Tribunal Penal } \\
\text { Internacional em casos de violência sexual na } \\
\text { antiga Iugoslávia. }\end{array}$ \\
\hline & Poncezk e Grezzana (2012) & $\begin{array}{l}\text { Analisaram mais de } 90 \text { mil conflitos trabalhistas } \\
\text { no Tribunal Superior do Trabalho: de maneira } \\
\text { geral, não encontram evidências de impacto de } \\
\text { gênero nas decisões daquele tribunal. }\end{array}$ \\
\hline \multirow[t]{2}{*}{$\begin{array}{l}\text { Composição e votação } \\
\text { em painéis, e efeito de } \\
\text { pares }\end{array}$} & Epstein, Landes e Posner (2013) & $\begin{array}{l}\text { Testam a ocorrência do efeito da composição do } \\
\text { painel, ou seja, votos decididos por unanimidade } \\
\text { ou por maioria. }\end{array}$ \\
\hline & Smyth (2005) & $\begin{array}{l}\text { Padrão de dissidência no Supremo Tribunal } \\
\text { Australiano por quase cem anos. }\end{array}$ \\
\hline \multirow[t]{5}{*}{$\begin{array}{l}\text { Mídia e opinião } \\
\text { popular }\end{array}$} & Epstein e Kobylka (1992) & $\begin{array}{l}\text { Segundo estes autores, a maior parte das decisões } \\
\text { judiciais reflete a opinião pública. }\end{array}$ \\
\hline & Casillas, Enns e Wohlfarth (2011) & $\begin{array}{l}\text { Encontram influência significativa da opinião } \\
\text { pública sobre as decisões da Suprema Corte dos } \\
\text { Estados Unidos. }\end{array}$ \\
\hline & $\begin{array}{l}\text { Giles, Blackstone e Vining Jr } \\
(2008)\end{array}$ & $\begin{array}{l}\text { Afirmam que há evidências claras de causalidade } \\
\text { na votação dos ministros. }\end{array}$ \\
\hline & Epstein e Martin (2010) & $\begin{array}{l}\text { Encontram provas de que as decisões da Suprema } \\
\text { Corte estão, em certo grau, alinhadas com a } \\
\text { opinião pública. }\end{array}$ \\
\hline & Lopes e Azevedo (2018) & $\begin{array}{l}\text { Comparando os impactos da pressão do Poder } \\
\text { Executivo (sobretudo da Presidência da } \\
\text { República) nas decisões do STJ e do STF. }\end{array}$ \\
\hline
\end{tabular}

Fonte: adaptado de Machado (2017).

Machado (2017) sugere ainda alguns temas que devem ser estudados no Brasil: relações contratuais; justiça trabalhista; justiça criminal; e, impactos de gênero.

Verifica-se, portanto, que o uso de métodos estatísticos aplicados à Ciência Jurídica, definida aqui de jurimetria, pode trazer benefícios, não só ao poder judiciário e aqueles que se utilizam da justiça brasileira, mas a toda sociedade, visto que propiciará uma maior celeridade processual, bem como contribuirá para uma maior assertividade nas decisões judiciais.

\subsection{Bibliometria: conceitos e leis}

Segundo Silva, Hayashi e Hayashi (2011) a origem do termo bibliometria tem sido atribuída, algumas vezes, a Paul Otlet em sua obra Traité de Documentation: Le Livre Sur Le 


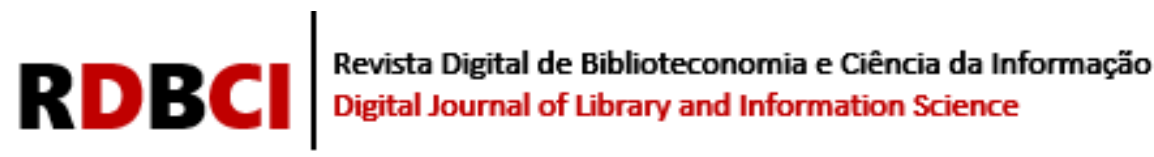

Livre, Theorie et Pratique (1934) e, outras, a Alan Pritchard, em seu livro Statistical Bibliography or Bibliometrics? (1969). No entanto, há que se destacar uma distinção entre os conceitos apresentados pelos autores. Enquanto que, para Otlet (1934) a bibliometria está inserida na bibliologia, para Pritchard (1969) a bibliometria tem sua equivalência à estatística bibliográfica, definindo-a como um termo mais adequado ao se fazer estatísticas de publicações científicas. Para Santos (2015, p. 5) "a palavra bibliometria é oriunda da fusão do sufixo 'metria' e de 'bibliografia', 'informação', 'ciência' e 'biblioteca', sendo respectivamente análogos ou próximos de sua natureza, objetivos e aplicações". De acordo com Alvarado (2002, p. 90), trata-se de um "conjunto de metodologias de pesquisa do campo das Ciências da Informação que aproveita análise quantitativa de dados, para explorar o arcabouço de uma área científica". Seja como for, trata-se de um conceito consolidado que gira ao redor da aplicação de métodos estatísticos sobre conteúdos bibliográficos (SILVA, HAYASHI e HAYASHI, 2011; YOSHIDA, 2010; CHUEKE e AMATUCCI, 2015).

Segundo Alvarado (2002), Araújo (2006) e Santos (2015), existem três leis clássicas na bibliometria: a Lei de Bradford (1934) que estuda a produtividade dos periódicos; a Lei de Lotka (1926) que trabalha com a produtividade científica dos autores; e, as leis de Zipf (2012) que analisam as frequências de ocorrências das palavras.

A Lei de Bradford, também chamada de Lei de Dispersão, "permite, mediante a medição da produtividade das revistas, estabelecer o núcleo e as áreas de dispersão sobre um determinado assunto em um mesmo conjunto de revistas" (VANTI, 2002, p. 153), conforme mostrado na Figura 1:

Figura 1. Lei de Bradford

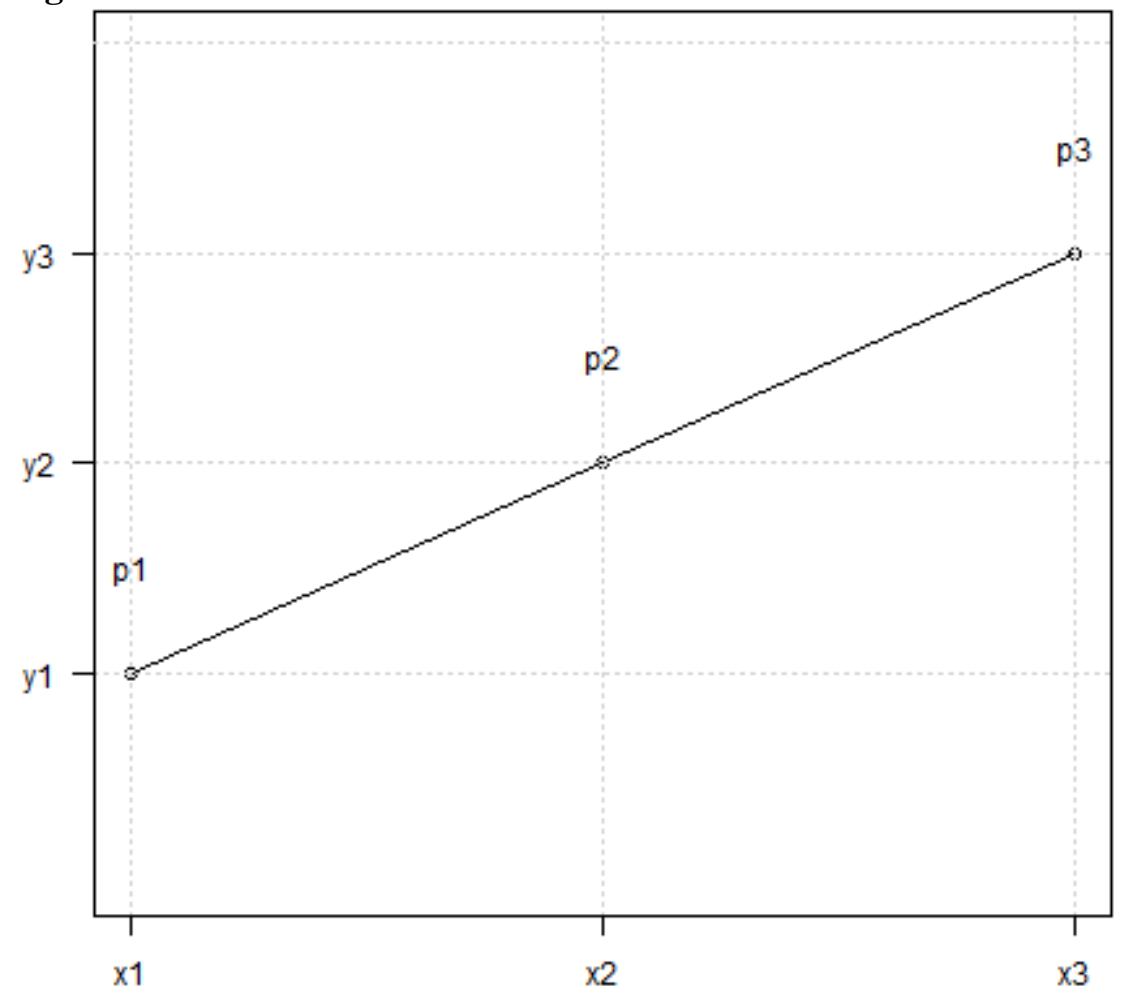

Fonte: adaptado de Vanti (2002).

A Lei de Bradford indica que há uma quantidade pequena de periódicos, os quais são "relacionados de maneira próxima ao assunto e um núcleo maior de periódicos relacionados de maneira estreita, sendo que o número de periódicos em cada zona aumenta, enquanto a produtividade diminui" (ARAÚJO, 2006, p. 14). Portanto, sugere-se que "à medida que novos 


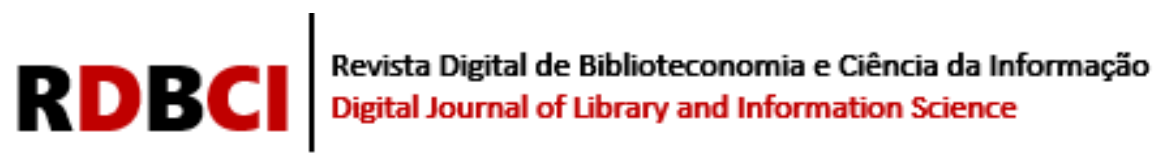

assuntos escritos forem surgindo, serão submetidos a uma pequena filtragem por periódicos, relacionados, quando aceitos. E por consequência, esses periódicos atraem mais e mais artigos, no decorrer do desenvolvimento da área" (SILVA, et al., 2012, p. 3).

A Lei de Lotka ou Lei dos Quadrados Inversos (LOTKA, 1926) tem por objetivo descrever o perfil das produções científicas dos autores, sendo que em sua maioria poucos autores produzem muito e muitos autores produzem pouco. Moretti e Campanario (2009, p. 70) assim a resumem: “o número de autores que fazem 'n' publicações sobre uma determinada área científica é de aproximadamente $1 / \mathrm{n}^{2}$ daqueles que fazem uma só publicação, sendo a proporção deste de aproximadamente $60 \%$ do conjunto de autores". A Lei de Lotka apresentou algumas reformulações, entre as quais, a substituição do Método do Quadrado Inverso pelo modelo do Poder Inverso Generalizado (PAO, 1985; NICHOLLS, 1986), conforme demonstrado por Cândido, et al., (2018), na Equação (1):

$$
\gamma_{x}=c x^{-n}
$$

Onde:

$\gamma_{x}=$ probabilidade de um autor contribuir com x publicações sobre um assunto;

$x=$ número de publicações sobre um determinado assunto encontradas em determinado período de tempo;

$c=$ porcentagem teórica dos autores que contribuíram com apenas um artigo, no espaço de tempo estudado (coeficiente de Lotka);

$n=$ declividade da Lei de Lotka.

De tal forma que $c$ é obtido pela Equação (2):

$$
c=\frac{1}{\sum_{x=1}^{P-1} \frac{1}{x^{n}}+\frac{1}{(n-1) P^{n-1}}+\frac{1}{2 P^{n}}+\frac{n}{24(P-1)^{n+1}}}
$$

Onde:

$x=$ número de publicações por autor;

$n=$ declividade da Lei de Lotka;

$P=$ número observado de pares.

E, por sua vez, $n$ é calculado conforme Equação (3):

$$
n=\frac{N \sum \log x \log y-\sum \log x \sum \log y}{N \sum \log x^{2}-\left(\sum \log x\right)^{2}}
$$

Onde:

$N=$ número de pares de dados (publicações por autor $\mathrm{X}$ autores);

$x=$ número de publicações por autor;

$y=$ número de autores em relação ao número de publicações;

A terceira lei clássica da bibliometria é a Lei de Zipf, a qual, segundo Araújo (2006, p. 16) "descreve a relação entre palavras num determinado texto suficientemente grande e a 


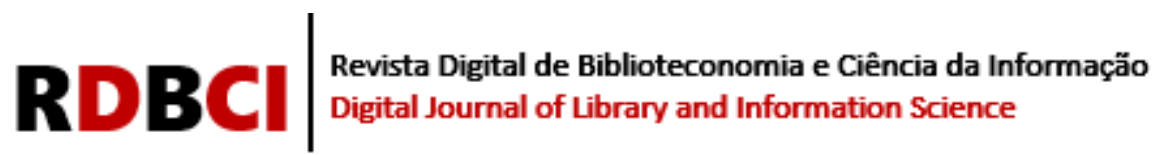

ordem de série destas palavras (contagem de palavras em largas amostragens)". Segundo Booth (1967) trata-se de uma lei originalmente proposta por Estoup (2018) em 1916 e popularizada por Zipf (2012) em 1949, cuja equação (4) é mostrada a seguir:

$$
c=r f
$$

Onde:

$c=$ valor constante para qualquer palavra de um texto em particular (constante de Zipf);

$r=$ posição da palavra em uma lista decrescente ordenada pela frequência;

$f=$ número de ocorrências da palavra.

Esta lei indica que "o produto da ordem de série (r) de uma palavra (dada pela frequência de ocorrência em ordem decrescente) pela sua frequência de ocorrência (f) era [é] aproximadamente constante" (GUEDES, 1994, p. 318). A partir daí, Zipf (2012) identificou que em um texto qualquer, palavras de baixa frequência apresentam, basicamente, a mesma frequência. Booth (1967) a interpreta conforme a Equação (5):

$$
\frac{I_{1}}{I_{n}}=\frac{n(n+1)}{2}
$$

Onde:

$I_{1}=$ número de palavras com frequência 1 ;

$I_{n}=$ número de palavras com frequência $n$;

$n=$ número de ocorrências de uma determinada palavra.

Neste ponto William Goffman "concluiu haver um ponto de transição entre as palavras de alta e de baixa frequências e que as palavras contidas nesse espaço teriam alto conteúdo semântico, ou seja, palavras que dão significado ao texto" (MELLO, 2017, p. 87). Tal conclusão, divulgada por Pao (1978), ficou conhecida por Ponto de Transição, indicando a "vizinhança onde [...] devem estar incluídas as palavras de maior conteúdo semântico", conforme Equação (6):

$$
n=\frac{-1+\sqrt{1+8 I_{1}}}{2}
$$

Onde:

$n=$ Ponto de Transição de Goffman, conhecido como T;

$I_{l}=$ número de palavras com frequência 1.

A partir da combinação das leis de Zipf e do Ponto de Transição de Goffman é possível estabelecer, graficamente, onde ocorre a transição de palavras de baixa para alta frequência, destacando as palavras que formam os conjuntos de informações triviais, interessantes e, simplesmente, ruídos, conforme mostrado na Figura 2: 


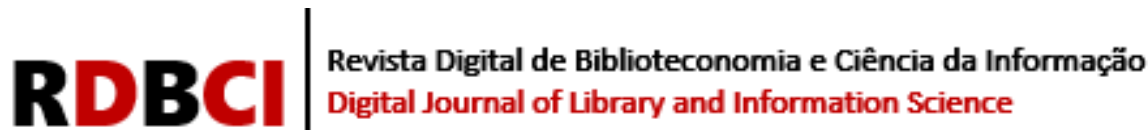

Figura 2. Zonas de ocorrências de palavras

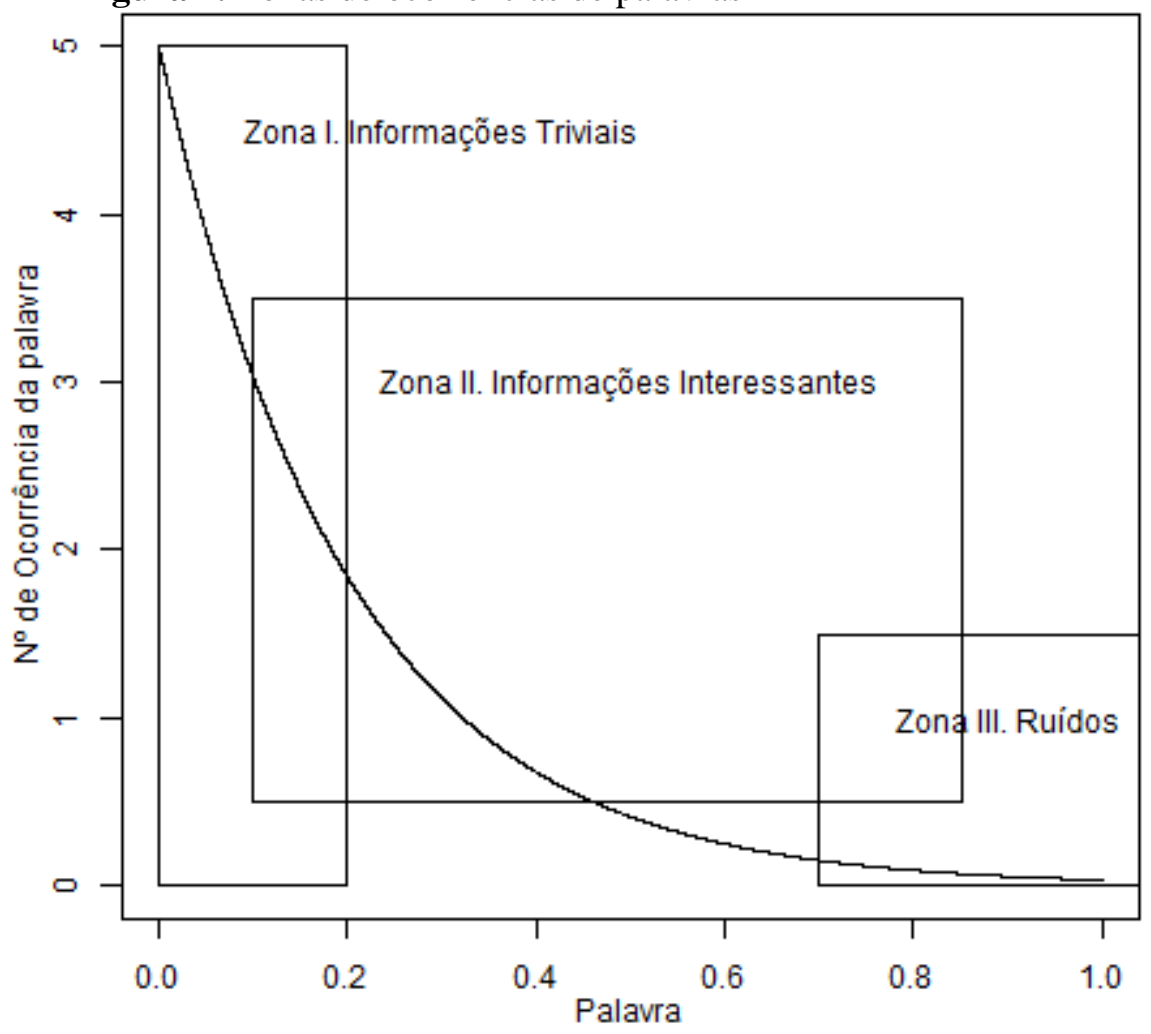

Fonte: adaptado de Quoniam, et al. (2001).

Evidentemente que a bibliometria não se resume a estas leis (FONSECA, 1986; CALLON, COURTIAL e PENAN, 1995; GINGRAS, 2016). Isto posto, considerando a importância das referências bibliográficas nos trabalhos científicos (MORAES, FURTADO e TOMAÉL, 2015), procurou-se verificar como se relacionam as citações e as referências de cada uma das obras, por meio de análise de citações.

"A Análise de Citações baseia-se na premissa de que os pesquisadores concebem seus trabalhos a partir de obras anteriores e demonstram isso citando as obras precedentes em seus textos e em uma lista ordenada e padronizada de referências" (MORAES, FURTADO e TOMAÉL, 2015, p. 186). Seu objetivo é "medir o impacto e a visibilidade de determinados autores dentro de uma comunidade científica" (VANZ e CAREGNATO, 2003, p. 251). Para atender este objetivo, Hirsch (2005) e Garfield (1956) propuseram ferramentas para avaliar a qualidade das publicações e mensurar a produtividade e o impacto do pesquisador. Eugene Garfield (1956) propôs o Fator de Impacto (FI): uma ferramenta de avaliação da qualidade das publicações, eficiente em avaliar a qualidade de um periódico. Para o cálculo do Fator de Impacto de um determinado ano "leva-se em consideração o número de citações recebidas naquele ano pelos artigos publicados pelo periódico nos dois anos precedentes, dividido pelo número de artigos publicados pelo periódico no mesmo período" (THOMAZ, ASSAD e MOREIRA, 2011, p. 90).

Jorge E. Hirsch (2005) propôs o Índice H, indicador responsável por mensurar a produtividade e o impacto do pesquisador, relacionando o número de publicações com o número de citações. "O índice $\mathrm{H}$ de um determinado autor será o número da sequência numérica dos trabalhos cujo número de citações iguala-se ou é maior que o ranque da sequência" (THOMAZ, ASSAD e MOREIRA, 2011, p. 92), conforme exemplo apresentado na Figura 3: 


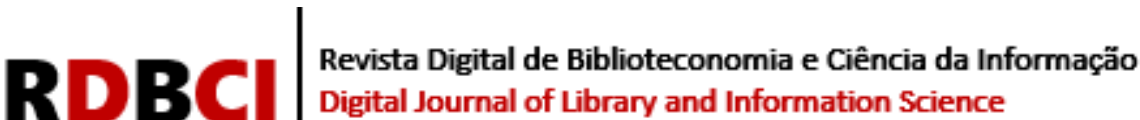

Figura 3. Exemplo de cálculo do índice $\mathrm{H}$

\begin{tabular}{|c|c|c|c|c|c|}
\hline Artigos do autor " $\mathrm{x}$ " & $\mathrm{N}^{\mathrm{o}}$ de citações & \multirow{6}{*}{ Ordenar $\rightarrow$} & Artigos do autor " $\mathrm{x}$ " & Ordem & $\mathrm{N}^{\mathrm{o}}$ de citações \\
\hline $\mathrm{A}$ & 20 & & $\mathrm{~A}$ & 1 & 20 \\
\hline $\mathrm{B}$ & 3 & & $\mathrm{D}$ & 2 & 10 \\
\hline $\mathrm{C}$ & 5 & & $E$ & 3 & 7 \\
\hline $\mathrm{D}$ & 10 & & $\mathrm{C}$ & 4 & 5 \\
\hline $\mathrm{E}$ & 7 & & B & 5 & 3 \\
\hline
\end{tabular}

É importante frisar que as leis aqui apresentadas não estão isentas de críticas: para autores como M. Carl Drott e Manfred Bonitz, falta a devida sustentação teórica à Lei de Bradford (BORGES, 2002); já C. Oppenheimer e Paul Travis Nicholls apontam para fragilidades na Lei de Lotka, associadas aos parâmetros de estimação (ALVARADO, 2002); quanto à Lei de Zipf, estudiosos como Pintadosi (2014), Manin (2008) e Aitchison, Corradi e Latham (2016) alertam para as armadilhas sinonímicas que podem afetar seus resultados. Por outro lado, existem trabalhos empregando mineração de textos, análise de redes sociais e geoanálise na exploração bibliométrica (FAVARETTO e FRANCISCO, 2017); técnicas de pesquisa operacional, como a programação linear e árvores de decisão (BORGES, 2002); distribuições teóricas de probabilidade e métodos de normalização aplicados ao número de citações, abordagens baseadas em percentis (MINGERS e LEYDESDORFF, 2015) e, até mesmo; abordagens qualitativas como a metassíntese (OLIVEIRA, LIMA e MORAIS, 2016).

\section{PROCEDIMENTOS METODOLÓGICOS}

Utilizando-se a categorização proposta por Silva e Menezes (2005), a presente pesquisa classifica-se como básica quanto a sua natureza, haja vista que tem por objetivo estudar as características da produção de artigos referente à jurimetria no Brasil; como quantitativa quanto à abordagem do problema, pois visa mensurar as publicações e suas especificidades; como exploratória em relação aos objetivos por explicitar como o assunto em questão vem sendo estudado no país; e sob o ponto de vista dos procedimentos técnicos, como bibliográfica, vez que o estudo é desenvolvido por meio de artigos publicados e encontrados na ferramenta de pesquisa Google Acadêmico.

A ferramenta de pesquisa Google Acadêmico foi definida como fonte para a composição de corpus de análise, tendo como marco temporal o período compreendido da data de publicação do primeiro artigo presente nesta base, até o dia 12 de agosto de 2019 (inclusive). A escolha desta ferramenta se deve ao fato de que o Google Acadêmico contém todas as publicações presente na base de Periódicos da Capes. Além de que, o Google Acadêmico tem se projetado como uma das principais ferramentas científicas de busca (FALAGAS, et al., 2008), uma vez que seus resultados são tão bons quanto a de outras bases científicas de pesquisa (HARZING e ALAKANGAS, 2016).

Os registros analisados foram obtidos a partir da busca pelo termo "jurimetria", acrescido dos filtros: (1) pesquisa em qualquer lugar do documento e, (2) exclusão de patentes e citações. A busca retornou 270 publicações, sendo que, deste total, foram retiradas as publicações repetidas, bem como os textos em língua inglesa e espanhola. Excluíram-se também todos os registros que não fossem artigos científicos. Por fim, chegou-se a um total de 84 artigos encontrados. Destes artigos extraíram-se as variáveis a serem analisadas, apresentadas no Quadro 2: 


\section{RDBCI}

Quadro 2. Variáveis de análise

\begin{tabular}{|l|l|l|}
\hline Variável & Natureza & O que se pretende analisar \\
\hline Título & Categórica & $\begin{array}{l}\text { Valores esperados do número de artigos científicos publicados no Brasil, } \\
\text { com o termo "jurimetria" no título. }\end{array}$ \\
\hline Revista & Categórica & $\begin{array}{l}\text { Valores esperados de autores e coautorias por artigo; números de artigos de } \\
\text { única autoria e de mais de um autor; artigos mais referenciados; índice de } \\
\text { colaboração (média do número de autores presentes na publicação em } \\
\text { relação ao número de publicações na literatura analisada, }\end{array}$ \\
\hline Ano de publicação & Categórica & Revistas que mais publicam sobre "jurimetria". \\
\hline Palavras-chave & Categórica & Distribuição do número de publicações ao longo dos anos. \\
\hline Referências & Categórica & $\begin{array}{l}\text { Palavras-chave que representam as informações mais frequentes sobre o } \\
\text { tema "jurimetria". }\end{array}$ \\
\hline
\end{tabular}

Fonte: os autores (2019).

As variáveis apresentadas no Quadro 2 foram submetidas ao protocolo de análise mostrado no Quadro 3:

Quadro 3. Protocolo de análise

\begin{tabular}{|c|l|l|}
\hline Etapa & Procedimentos & Objetivos \\
\hline 1 & $\begin{array}{l}\text { Estatísticas descritivas: freqüências, médias, desvios } \\
\text { padrão, mínimos e máximos. }\end{array}$ & Descrever o conjunto de dados. \\
\hline 2 & Lei de Lotka. & Encontrar a produtividade científica dos autores. \\
\hline 3 & Lei de Bradford. & Identificar as zonas de produtividade das revistas. \\
\hline 4 & Leis de Zipf e Ponto de Transição de Goffman. & Identificar as palavras-chave mais relevantes. \\
\hline 5 & Análise de citações por meio do índice de H. & Identificar os autores mais citados. \\
\hline
\end{tabular}

Fonte: os autores (2019).

A análise dos dados foi realizada no software $\mathrm{R}$ versão 3.5.1, empregando-se o pacote bibliometrics (ARIA e CUCCURULLO, 2017). Já os dados referenciais dos 84 artigos foram salvos no formato BibTex, exportados para o formato xlxs e tabulados no software Microsoft Excel 2010.

\section{ANÁLISE E DISCUSSÃO DOS RESULTADOS}

Nos 84 artigos analisados, verificou-se que a primeira obra foi publicada em 2002 trata-se do artigo "O direito informático" de José Augusto Delgado. Depois deste registro, houve um lapso temporal de seis anos até a próxima publicação em 2008. Desta data em diante, em todos os anos houveram publicações relacionadas ao tema pesquisado, conforme mostrado na Figura 4: 


\section{\begin{tabular}{l|l} 
Revista Digital de Biblioteconomia e Ciência da Informação \\
Digital Journal of Library and Information Science
\end{tabular}}

Figura 4. Número de publicações de 2002 a 2019

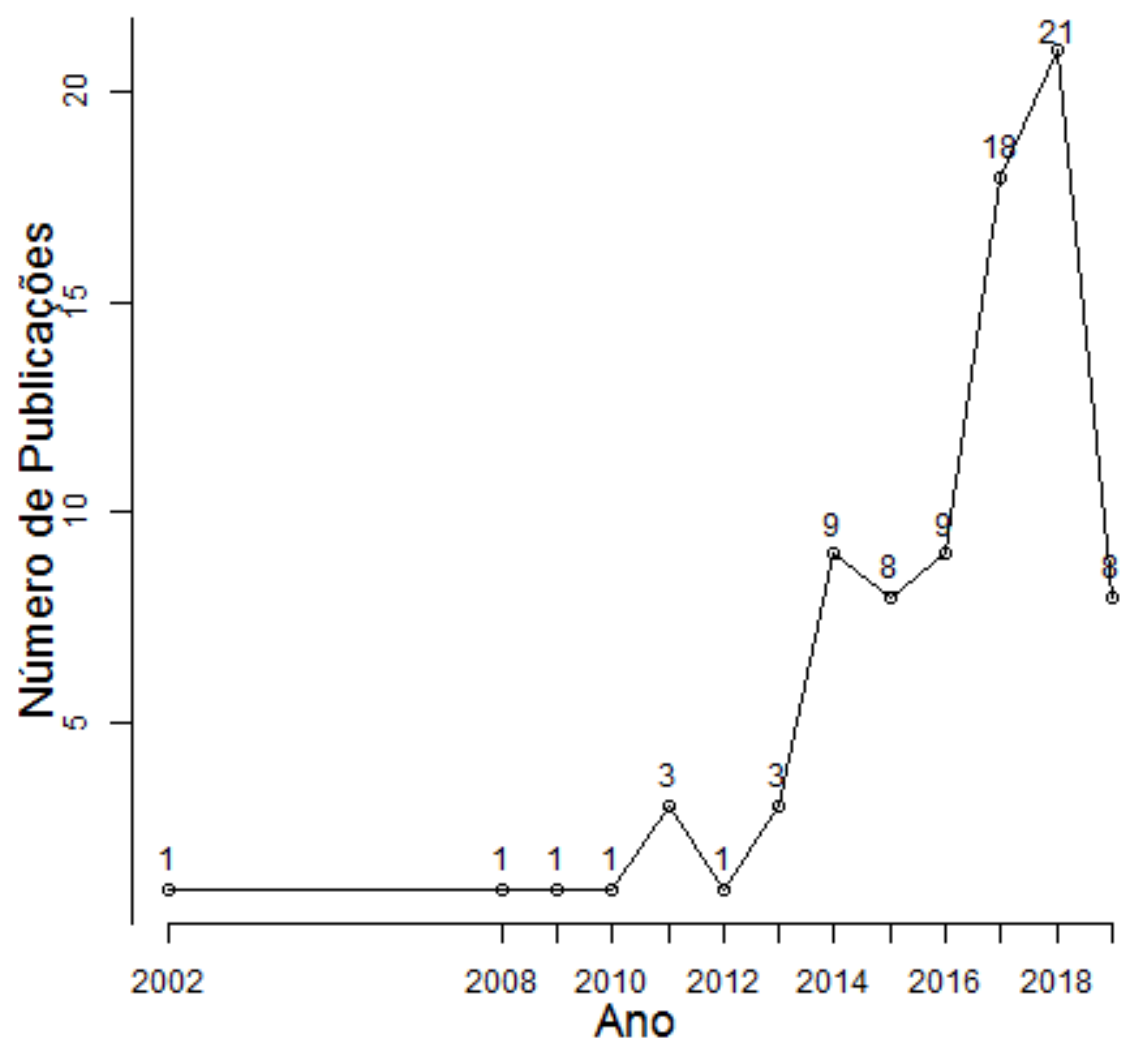

Fonte: dados da pesquisa (2019).

É possível notar, portanto, um nítido aumento no número de publicações principalmente do ano de $2013 \mathrm{em}$ diante. Analisando todo o período, houve um crescimento médio anual de $18,92 \%$.

Já a Tabela 1 mostra as estatísticas descritivas associadas aos números de artigos e autores:

Tabela 1. Artigos e autorias

\begin{tabular}{lrccc}
\hline Variáveis & Média & Desvio padrão & Mínimo & Máximo \\
\hline Artigos por autor & 0,58 & 0,59 & 1 & 4 \\
Autores por artigo & 1,70 & 1,19 & 1 & 9 \\
Coautoria por artigo & 1,85 & 1,55 & 0 & 8 \\
\hline
\end{tabular}

Fonte: dados da pesquisa (2019).

Observa-se que a maioria dos artigos $(75,72 \%)$ apresentam mais de um autor, elevando as estatísticas de média de coautoria e número médio de autores por artigo para quase dois. De maneira geral, o índice de colaboração atingiu o valor de 2,32, o que significa que há em média 2,32 autores colaborando por artigo. Registrou-se também que 36 artigos de única autoria e 109 artigos com mais de um autor.

Por sua vez, o Quadro 4 apresenta os autores que produziram mais de um artigo no período estudado:

Quadro 4. Autores presentes em mais de um artigo

\begin{tabular}{|l|l|c|}
\hline Autor & Título & Ano \\
\hline $\begin{array}{l}\text { Daniel Francisco } \\
\text { Nagao Menezes }\end{array}$ & $\begin{array}{l}\text { Breve análise sobre a jurimetria, os desafios para a sua implementação e as vantagens } \\
\text { correspondentes }\end{array}$ & 2017 \\
\cline { 2 - 3 } & $\begin{array}{l}\text { Efetividade do direito a educação na Jurisprudência do Tribunal de Justiça do Estado de São } \\
\text { Paulo a Luz da Jurimetria }\end{array}$ & 2017 \\
\cline { 2 - 3 } & Região Metropolitana de Campinas: PIB X Processos Trabalhistas - Análise Jurimétrica. & 2014 \\
\hline
\end{tabular}




\section{RDBCI $=$ Digital Journal of Library and Information Science}

\begin{tabular}{|c|c|c|}
\hline & Jurimetria: Análise da ineficácia do poder judiciário na proteção do consumidor & 2014 \\
\hline \multirow[t]{3}{*}{ Filipe Jaeger Zabala } & Pesquisa aplicada em software livre na aprendizagem de Matemática e Estatística & 2018 \\
\hline & Avaliação e correção automática no software livre RStudio & 2016 \\
\hline & Jurimetria: estatística aplicada ao Direito & 2014 \\
\hline \multirow{2}{*}{$\begin{array}{l}\text { Grazielly } \\
\text { Alessandra } \\
\text { Baggenstoss }\end{array}$} & $\begin{array}{l}\text { Hermenêutica jurídica nos tribunais superiores brasileiros: Pesquisa amostral das decisões } \\
\text { judiciais }\end{array}$ & 2014 \\
\hline & A decisão judicial no constitucionalismo garantista & 2013 \\
\hline \multirow[t]{2}{*}{$\begin{array}{l}\text { Mônica Bonetti } \\
\text { Couto }\end{array}$} & $\begin{array}{l}\text { Gestão da justiça e do conhecimento: a contribuição da jurimetria para a administração da } \\
\text { justiça }\end{array}$ & 2016 \\
\hline & A ética utilitarista e a pesquisa empírica qualitativa no Direito & 2015 \\
\hline \multirow[t]{2}{*}{$\begin{array}{l}\text { Simone Pereira de } \\
\text { Oliveira }\end{array}$} & $\begin{array}{l}\text { Gestão da justiça e do conhecimento: a contribuição da jurimetria para a administração da } \\
\text { justiça }\end{array}$ & 2016 \\
\hline & A ética utilitarista e a pesquisa empírica qualitativa no Direito & 2015 \\
\hline \multirow[t]{2}{*}{$\begin{array}{l}\text { Alexandre Rocha } \\
\text { Almeida de Moraes }\end{array}$} & $\begin{array}{l}\text { Um novo modelo de atuação criminal para o Ministério Publico brasileiro: agencias e } \\
\text { laboratório de jurimetria }\end{array}$ & 2018 \\
\hline & $\begin{array}{l}\text { Novas perspectivas de atuação criminal do Ministério Publico no controle social da } \\
\text { criminalidade }\end{array}$ & 2017 \\
\hline \multirow{2}{*}{$\begin{array}{l}\text { Thaisa Jacintho } \\
\text { Muller }\end{array}$} & Pesquisa aplicada em software livre na aprendizagem de Matemática e Estatística & 2018 \\
\hline & Avaliação e correção automática no software livre RStudio & 2016 \\
\hline \multirow{2}{*}{$\begin{array}{l}\text { Márcia Carla } \\
\text { Pereira Ribeiro }\end{array}$} & Mecanismos jurídicos e econômicos para a transferência de tecnologia: um estudo de caso & 2017 \\
\hline & $\begin{array}{l}\text { O "Modelo dos Limões" aplicado ao contrato sob o regime jurídico de transferência de } \\
\text { estabelecimento empresarial: uma analise econômica do Direito }\end{array}$ & 2015 \\
\hline \multirow{2}{*}{$\begin{array}{l}\text { Marcelo Guedes } \\
\text { Nunes }\end{array}$} & Recuperação judicial no estado de São Paulo - $2^{a}$ fase do observatório de insolvência & 2019 \\
\hline & Reformas de decisão nas câmaras de direito criminal em São Paulo & 2015 \\
\hline
\end{tabular}

Fonte: dados da pesquisa (2019).

Ou seja, dos 84 artigos analisados, 63 deles foram escritos por autores que não produziram outros artigos disponibilizados na base estudada. Com a finalidade de descrever a frequência de publicação dos autores, calculou-se o coeficiente de Lotka, cujo resultado de 3,77 indica que o número de autores que escrevem dois artigos seria igual a $0,073\left(1 / 2^{3,77}\right)$ do número de autores que escreveram apenas um artigo.

Tendo uma vez identificados os autores com maior número de produções nos termos desta pesquisa, averiguaram-se as revistas com maior incidência de artigos publicados. Os resultados são apresentados na Tabela 2:

Tabela 2. Revistas com mais de um artigo

\begin{tabular}{lc}
\hline Nome da Revista & Número de publicações \\
\hline Revista da Faculdade de Direito da Universidade Federal de Minas Gerais & 4 \\
Brazilian Journal of Empirical Legal Studies & 2 \\
Direito UNIFACS - Debate Virtual & 2 \\
Prensas de la Universidad de Zaragoza & 2 \\
Revista Direito e Liberdade & 2 \\
Revista dos Tribunais Online & 2 \\
Revista Jurídica da Escola Superior do Ministério Público de São Paulo & 2 \\
Revista Opinião Jurídica & 2 \\
\hline
\end{tabular}

Fonte: dados da pesquisa (2019).

De acordo com a Lei de Bradford, constata-se que uma revista apresenta quatro artigos, sete revistas dois artigos e 56 revistas um único artigo. Portanto, corrobora-se que muitos periódicos produzem pouco sobre a área investigada, conforme Figura 5: 


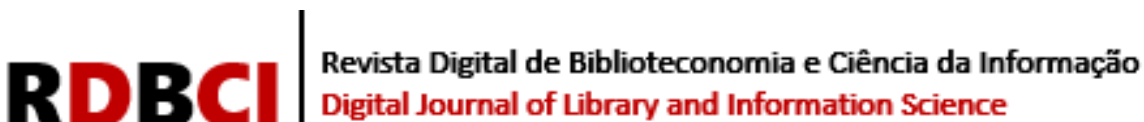

Figura 5. Número de revistas por número de publicações

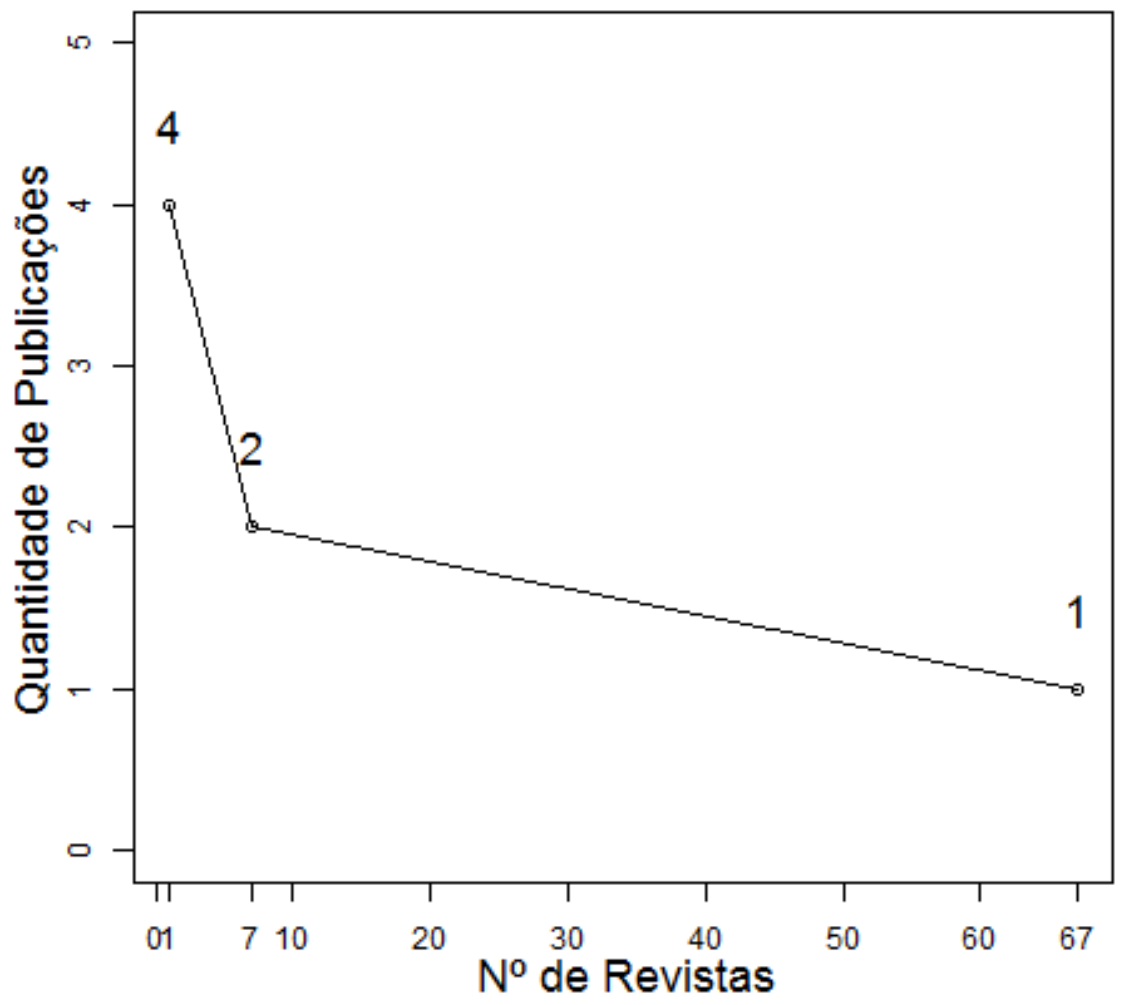

Fonte: dados da pesquisa (2019).

Em relação às palavras-chave, a Tabela 3 apresenta um resumo quantitativo das ocorrências encontradas:

Tabela 3. Palavras-chave

\begin{tabular}{ccl}
\hline $\begin{array}{c}\text { Frequências das } \\
\text { palavras-chave }\end{array}$ & $\begin{array}{c}\text { Quantidade de } \\
\text { palavras-chave }\end{array}$ & Palavras-chave \\
\hline 21 & 1 & $\begin{array}{l}\text { Jurimetria } \\
\text { Direito; estatística; inteligência artificial } \\
\text { Adoção; processo civil } \\
\text { Análise lógica; ato invalido e ato ilícito; código de processo civil; decisão } \\
\text { judicial; direitos humanos; dissolução parcial; incidência sucessiva; } \\
\text { interdisciplinaridade; ministério público; morosidade; plano de validade; poder } \\
\text { judiciário; processamento de linguagem natural; rstudio; segurança; supremo } \\
\text { tribunal federal } \\
\text {... }\end{array}$ \\
2 & 16 & \\
\hline
\end{tabular}

Fonte: dados da pesquisa (2019).

Excetuando-se a palavra "jurimetria" (justamente o termo utilizado na busca), se destacam os termos "adoção" e "processo civil", mostrando as áreas do Direito com mais aplicações de jurimetria. Logo depois, as palavras "direito" e "estatística", presente em cinco artigos, evidenciam a própria definição de jurimetria (estatística aplicada ao Direito). Além destas, também na mesma posição quanto ao número de ocorrências, destaca-se o uso de "inteligência artificial" indicando a aplicação de sistemas computacionais capazes de atuar de maneira similar à humana, no campo do Direito.

Excluindo-se a palavra "jurimetria" e aplicando a $1^{\mathrm{a}}$ Lei de Zipf às demais palavras-chave, ordenadas de forma decrescente de acordo com a frequência de ocorrência, obtêm-se os valores mostrados na Tabela 4: 


\section{RDBCI $=$}

Tabela 4. $1^{\mathrm{a}}$ Lei de Zipf

\begin{tabular}{cccc}
\hline Quantidade de palavras-chave & Ordem de série (r) & Frequência (f) & Constante de Zipf \\
\hline 3 & 1 & 5 & 5 \\
2 & 2 & 3 & 6 \\
16 & 3 & 2 & 6 \\
253 & 4 & 1 & 4 \\
\hline
\end{tabular}

Fonte: dados da pesquisa (2019).

Ao se plotar as constantes de Zipf em relação às ordens da série, encontrados na Tabela 4, obtém-se a Figura 6:

Figura 6. Zonas de ocorrências de palavras-chave

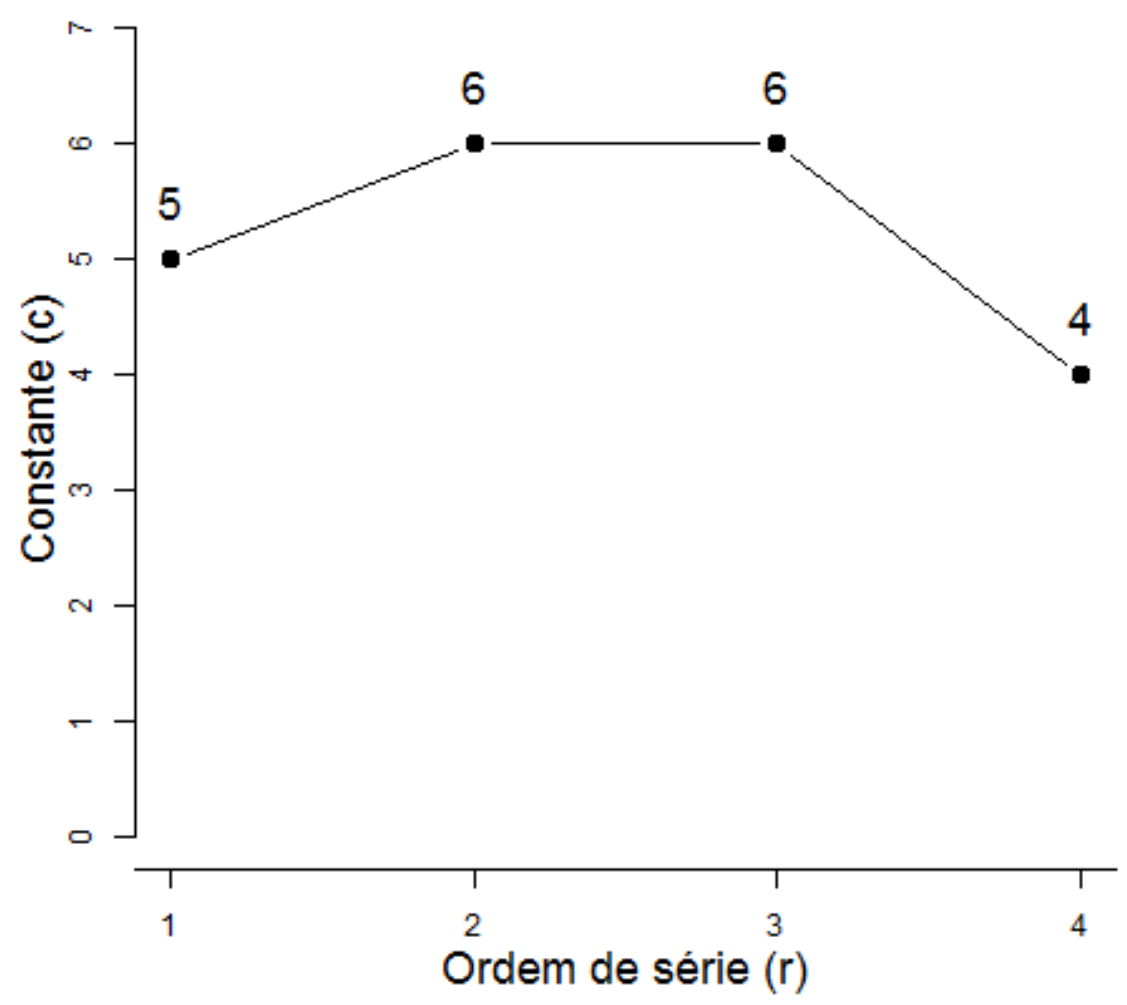

Fonte: dados da pesquisa (2019).

Pode-se observar que o ponto de transição entre as palavras de alta e de baixa frequência é aquela que possui a constante de Zipf igual a seis, haja vista que as palavras: jurimetria; direito; estatística; inteligência artificial são consideradas como informações triviais (Zona I, conforme proposto por Zipf) e as palavras com constante de Zipf igual a quatro são consideradas como ruídos (Zona III). Desta forma, a fim de se identificar qual é a palavra que separa a zona de informações triviais da zona de ruídos, calculou-se o Ponto de Transição de Goffman ( $\mathrm{T}$ ) que, ao retornar um valor de $\mathrm{T}$ igual a 22 , indica que a $22^{\mathrm{a}}$ palavra chave é a que exibe esta transição, conforme apresentado na Tabela 5:

Tabela 5. Palavras-chave para o Ponto de Transição de Goffman

\begin{tabular}{llc}
\hline $\begin{array}{l}\text { Zonas de ocorrência de } \\
\text { palavras }\end{array}$ & Palavras & Ordem \\
\hline Zona I. Informações & Jurimetria & - \\
Triviais & & 1 \\
\hline Zona II. Informação & Direito & 2 \\
Interessante & Estatística & 3 \\
& Inteligência artificial & 4 \\
& Adoção & 5 \\
& Processo civil & 6 \\
\hline
\end{tabular}




\section{$\mathrm{RDBC} \mid=$}

$\begin{array}{ll}\text { Ato inválido e ato ilícito } & 7\end{array}$

Código de processo civil

Decisão judicial

Direitos humanos 10

Dissolução parcial 11

Incidência sucessiva 12

Interdisciplinaridade 13

Ministério público 14

Morosidade 15

$\begin{array}{lr}\text { Plano da validade } & 16\end{array}$

$\begin{array}{ll}\text { Poder judiciário } & 17\end{array}$

Processamento de linguagem natural 18

$\begin{array}{lr}\text { Rstudio } & 19\end{array}$

Segurança 20

Supremo tribunal federal 21

Associação Brasileira de Lawtechs e Legaltechs $\quad 22$

Zona III. Ruídos Acesso justiça; Acolhimento institucional; Acórdão; Actio nata; Administração pública; Administradores judiciais; Adoção brasileira; Adoção consensual; Adoção intuitu personae; Afeto; Agencia; Agente infiltrado Analise de métodos; Analise econômica; Analise econômica do direito; Analise empírica das decisões judiciais; Analise jurisprudencial; Analise semântica latente Ancoragem; Aplicação de computador; Aprendizado ativo; Apuração de haveres; Argumentação jurídica; Art 1085 do código civil; Ativismo; Ativos intangíveis de identidade comercial; Ativos intangíveis e propriedade intelectual; Atuação criminal e eficiência; Audiência de conciliação; Autonomia; Autonomia patrimonial; Avaliação de desempenho; Avaliação judicial; Bankruptcy Law; Bases eletrônicas de julgados; Bem ambiental; Big data; Biogás; Bricolagem metodológica; Cadastro nacional de adoção CNA; Campanhas de adoção; Carf; Ciência do direito; Cinema; Civil Law; Cláusulas contratuais gerais; Comercio eletrônico; Common Law; Comunicação; Concursos; Conflito entre sócios; Conflito positivo; Conflitos de massa; Conflitos entre nome de domínio na internet e marcas registradas; Conselheiros; Consequencialismo; Constitucionalidade; Constitucionalismo; Contencioso administrativo; Contencioso de massa; Contraditório; Contratos; Controvérsias; Cooperação; Corrupção; Criança e adolescente; Crime organizado; Cuidado; Dados abertos; Dano moral; Demanda repetitiva; Derivativos; Desapropriação; Desempenho judiciário; Desigualdades sociais; Dignidade humana; Direito alternativo; Direito civil; Direito comercial; Direito comercial brasileiro; Direito comparado; Direito criminal; Direito da infância e da juventude; Direito das famílias; Direito do consumidor; Direito educação; Direito eletrônico; Direito internacional; Direito privado; Direito processual civil; Direito social; Direito societário; Direitos fundamentais;Economia; Economia comportamental; Efeitos econômicos; Efetividade; Efetividade do direito privado; Eficiência judicial; Eficiência processual; Empiria; Empirical legal research; Ensino jurídico; Entity shielding; Entraves e obstáculos; Entrega voluntaria; Epistemologia; Estado democrático de direito; Estado regulatório; Estatal; Estatística jurídica; Estudos empíricos legais; Exclusão extrajudicial de sócio minoritário; Exercicio da cidadania; Exigibilidade; Falencia; Familia; Familia biologica ou de origem; Familia substituta; Filosofia; Framing; Gameficacao; Gestão da justiça; Ghost in the shell; Governo aberto; Governo estadual; Habeas corpus; Hermenêutica jurídica; Heterogeneidade de cálculos; Homo economicus; Impacto da decisão judicial; Inércia; Informação; Informação assimétrica; Informática jurídica; Insolvency Law; Inteligência artificial e direito; Inteligência cognitiva; Interdependência funcional; Interesse publico; Internacionalização; Internet; Interoperabilidade; Interpretação; Juiz natural; Julgador; Julgados brasileiros; Jurídica; Jurismetria; Lawtechs; Learning with free software; Lee loevinger; Legalidade; Lei de acesso informação; Liberdade de iniciativa; Litigantes habituais; Litigância repetitiva; Lógica indutiva; Luta de classes; Markdown; Matemática básica; Matrizes de analise; Mediação; Mercosul; Metodologia mcda c; Motivacao; Mundo virtual; Mutuo bancário; Negócios e contratos; Nível de proteção; Novo código de processo civil; Online dispute resolution; Ontologias; Operadores do direito; Otimismo; Owner shielding; Pan principiologismo; Personalidade jurídica; Pesquisa aplicada em direito; Pesquisa de jurisprudência; Pesquisa empírica; Pesquisa empírica qualitativa; Pesquisa virtual; Pluralismo metodológico; Poder 


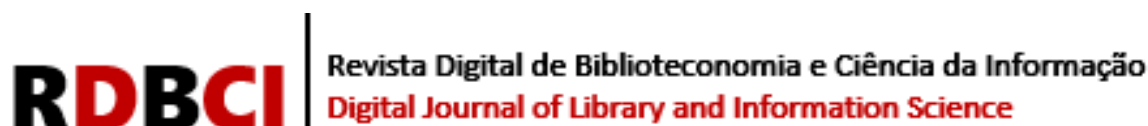

geral de cautela; Política criminal e dogmática penal; Política judiciária; Políticas públicas; Positivismo; Pratica jurídica; Precedente judicial; Precedentes vinculantes; Prevenção criminal; Princípio da eficiência; Princípios; Privacidade; Privado; Processo coletivo; Processo eletrônico; Processo judicial eletrônico; Processos judiciais; Processos trabalhistas; Procuradoria; Programa de protecao ao emprego; Projeto pensando o direito; Protagonismo judicial; Proteção ao investimento privado; Proteção distintiva de empresas; Proteção jurídica do investimento privado código comercial; Proteção propriedade intelectual; Publico; R Studio; Racionalidade forte; Reconhecimento de padrões; Recuperação de empresas; Redução da jornada de trabalho; Redução salarial; Reforma de decisão; Reintegração familiar; Relação de consumo; Relação entre os gêneros; Relações jurídicas; Repercussão geral; Research in education; Responsabilidade limitada; Responsividade; Scientific methodology; Seleção; Seleção adversa; Setor público; Shiny; Simbolismo dos códigos; Sistema multiportas; Sistema R; Sistemas baseados em conhecimento jurídico; Sociedade da informação; Sociedades comerciais; Tecnologias sociais; Telefonia; Teoria do garantismo jurídico; Testamento vital; Tipos societários; Tomada de decisão; Tópica; Transferência de tecnologia; Transferências de estabelecimentos empresariais; Transparência; Utilitarismo; Vantagens e resultados; Violência doméstica; Virtual; Vulnerabilidade do consumidor.

Fonte: dados da pesquisa (2019).

Seguindo o protocolo de análise, por fim, analisou-se o comportamento das citações, a fim de se identificar quais obras e/ou autores estão sendo utilizados ao se trabalhar com o referido tema. As publicações que foram mais citadas nos artigos analisados são apresentadas na Tabela 6:

Tabela 6. Publicações mais citadas

\begin{tabular}{lllc}
\hline Autor & Título & Ano & Frequência \\
\hline Lee Loevinger & Jurimetrics: The Methodology of Legal Inquiry & 1963 & 7 \\
Filipe Jaeger Zabala e & Jurimetria: estatística aplicada ao Direito & 2014 & 6 \\
$\begin{array}{l}\text { Fabiano Feijó Silveira } \\
\text { Lee Loevinger }\end{array}$ & Jurimetrics - The Next Step Forward & 1949 & 4 \\
Marcelo Guedes Nunes & $\begin{array}{l}\text { Jurimetria aplicada ao direito societário - um estudo } \\
\text { estatístico da dissolução de sociedade no Brasil }\end{array}$ & 2012 & 4 \\
Marcelo Guedes Nunes & Jurimetria: como a estatística pode reinventar o Direito & 2016 & 4 \\
Mauro Cappelletti Bryant & Acesso à justiça & 1988 & 3 \\
Garth & & 2012 & 3 \\
Fábio Ulhoa Coelho & Curso de Direito Comercial: Direito de Empresa & 2003 & 3 \\
Marcos Bernardes de Mello & Teoria do Fato Jurídico - plano da existência & 3 \\
Márcia Milena Pivatto Serra & Como utilizar elementos da estatística descritiva na & 2013 & \\
& jurimetria & & \\
\hline
\end{tabular}

Fonte: dados da pesquisa (2019).

As obras de Lee Loevinger, encontradas na pesquisa, fizeram com que este autor fosse citado mais frequentemente, incluindo-se, também, o fato de ser considerado o precursor do termo em estudo (GARGANO e NADER, 2018; LUVIZOTTO e GARCIA, 2020).

Dadas as publicações mais citadas, calculou-se o Índice $H$, indicador responsável por mensurar a produtividade e o impacto do pesquisador, relacionando o número de publicações de um autor com o número de citações. Para o caso analisado, chegou-se a um índice de $\mathrm{H}$ igual a 4, ou seja, pelo menos quatro dos autores mais citados possuem quatro ou mais citações. Analisando as co-citações, percebe-se a relação apresentada na Figura 7: 


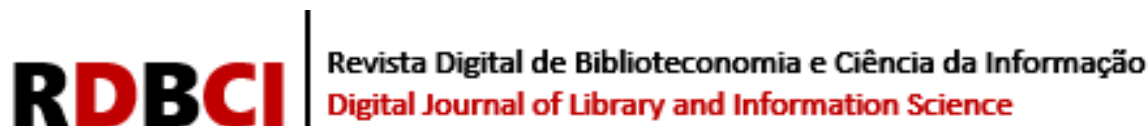

Figura 7. Rede de co-citações
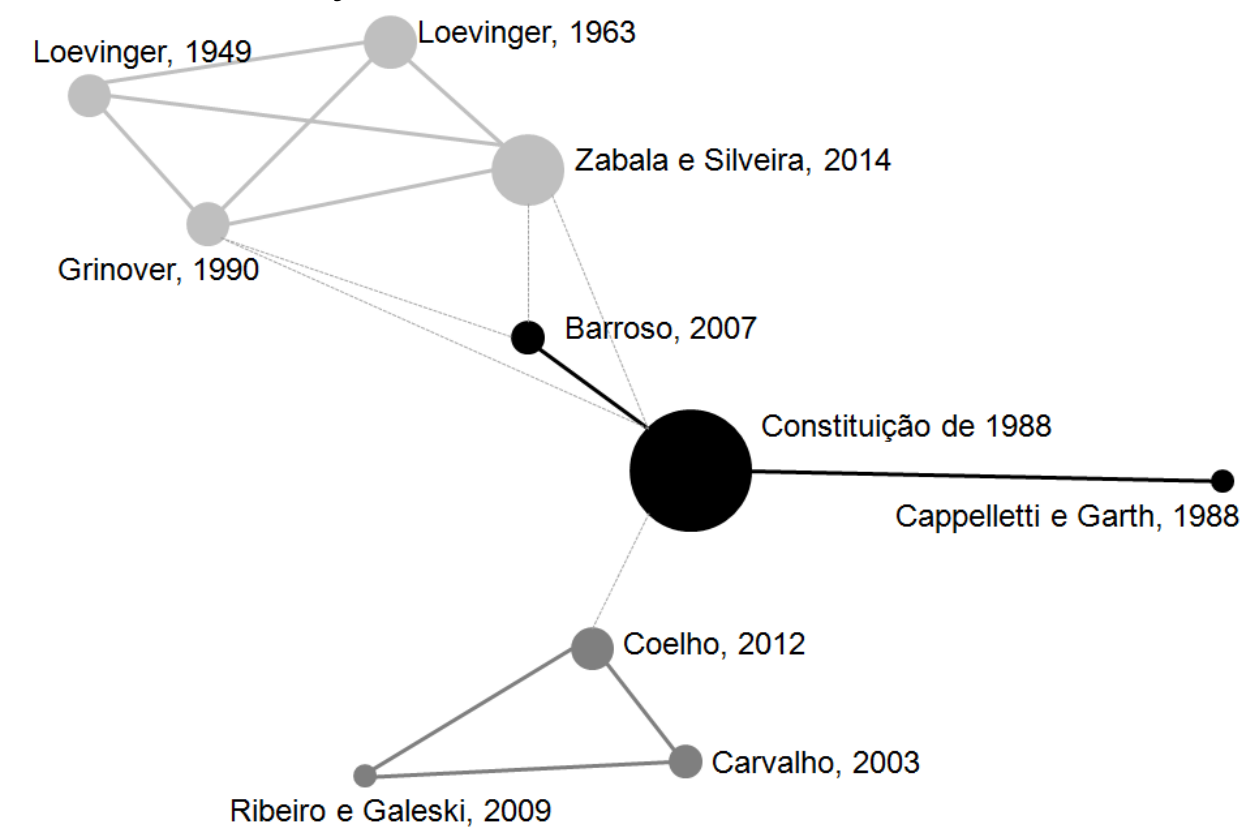

Fonte: dados da pesquisa (2019).

Na Figura 7, observa-se a relação apresentada por cada autor sobre outros indivíduos, constatando-se uma predominância da Constituição da República Federativa do Brasil de 1988.

É importante analisar os resultados encontrados à luz de outros estudos. Neste sentido, corroborando com as leis de Bradford (1934) e Lotka (1926), os achados apontam para uma concentração, em termos de autores e revistas, que atuam sobre este tema. Ou seja, ainda que se tenha tido um aumento médio de publicações, de 2002 a agosto de 2019, de 18,92\%, verifica-se a presença de poucos autores e revistas publicando sobre jurimetria - o que corrobora com estudos anteriores, que enfatizam se tratar de tema recente e ainda pouco explorado no Brasil (MENEZES e BARROS, 2017; ZABALA e SILVEIRA, 2014; YEUNG, 2017).

Quanto ao que tem sido publicado, a partir da classificação de palavras-chaves proposta por Zipf (2012), pode-se identificar temas recorrentemente abordados. Se, por um lado, as palavras-chaves identificadas como "Informação interessante" apresentam significados abrangentes (por exemplo, "Direito", "Decisão judicial", "Morosidade") ao, a partir delas, se realizar uma busca junto aos chamados "Ruídos", obtém-se um cenário mais preciso sobre os estudos publicados:

- Destacam-se os temas associados ao Direito da Família, pois a partir do termo "Adoção", na "Informação interessante", pode-se rastrear "Ruídos" de significado semântico semelhantes, a saber: "direito da infância e da juventude"; "direito das famílias"; "adoção brasileira"; "adoção consensual"; "adoção intuitu personae"; "afeto"; "cadastro nacional de adoção (CNA)"; "campanhas de adoção"; "criança e adolescente"; "entrega voluntaria"; "família"; "família biológica ou de origem"; "família substituta"; "reintegração familiar".

- Da mesma forma, tomando-se a informação interessante "Dissolução parcial", é possível rastrear, junto aos "Ruídos", os termos "direito comercial"; "direito comercial brasileiro"; "direito societário"; "dissolução parcial"; "exclusão extrajudicial de sócio minoritário"; "conflito entre sócios"; "conflito positivo"; "conflitos de massa"; "falência"; "proteção distintiva de empresas"; "proteção 


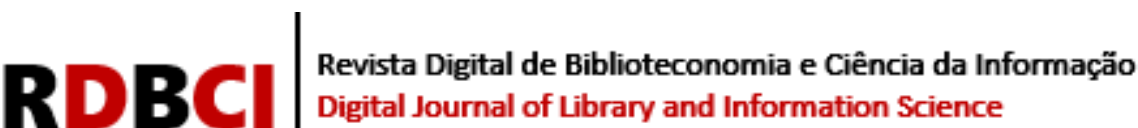

jurídica do investimento privado"; "código comercial"; "recuperação de empresas"; "tipos societários"; "transferências de estabelecimentos empresariais"; "mutuo bancário"; "negócios e contrato".

- É possível, também, notar a presença de estudos preocupados com as decisões em si (ainda que em menor número), visto que a partir do termo "Decisão judicial" ("Informação interessante"), registra-se junto aos "Ruídos" as palavras-chaves "analise empírica das decisões judiciais"; "analise jurisprudencial"; "desempenho judiciário"; "eficiência judicial"; "eficiência processual"; "impacto da decisão judicial".

Yeung (2017) coloca que, apesar de que no Brasil, a jurimetria encontra-se em fase inicial quanto às comunicações científicas, este tema poderia ser de grande valor quando associado a questões como relações contratuais, sobretudo envolvendo dívidas e bancos; justiça trabalhista; justiça criminal; e, impactos de gênero em decisões judiciais. Neste sentido, a colocação de Yeung (2017) parece ter sido considerada em significativa parte dos artigos publicados.

A presença de Lee Loevinger como o autor mais frequentemente citado não causa estranheza, visto ter sido um dos precursores do estudo da jurimetria (COUTO e OLIVEIRA, 2016; BISPO e GONÇALVES, 2019; DUARTE e NUNES, 2020).

Finalmente, no que se refere à análise das citações e co-citações, o destaque vai para a própria Constituição de 1988, haja vista a importância da Carta Magna junto aos estudos jurídicos. Além disso, constata-se grande frequência de citação nas obras de Lee Loevinger, primeira pessoa a utilizar o termo jurimetria (NUNES, 2016).

\section{CONSIDERAÇÕES FINAIS}

Ao finalizar o presente estudo, faz-se importante levantar os principais resultados encontrados. Neste sentido, entre 2002 e agosto de 2019, pode se encontrar 84 artigos científicos publicados no Brasil sob o tema jurimetria, evidenciando um crescimento médio anual de 18,92\%. Dos artigos publicados, há quase dois autores por obra, sendo que 36 publicaram sozinhos de um total de 143 autores. Dois autores se destacaram: Daniel Francisco N. Menezes e Filipe J. Zabala, o primeiro com quatro e o segundo com três publicações. A Revista da Faculdade de Direito da Universidade Federal de Minas Gerais foi o periódico mais publicações com o tema. Palavras relacionadas à estatística, poder judiciário e ao direito civil (Adoção; Processo civil; Ato inválido e ato ilícito; Código de processo civil; Dissolução parcial; Incidência sucessiva) foram classificadas como zona de interesse, segundo a Lei de Zipf, o que sugere o Direito Civil como uma área do direito mais alinhada ao uso da jurimetria. Lee Loevinger foi o autor mais citado nas obras, em decorrência de ser considerado o precursor do termo em estudo. Autores brasileiros como Filipe J. Zabala, Fabiano F. Silveira e Marcelo G. Nunes também obtiveram destaque.

Como limitação, este trabalho explorou apenas a ferramenta de pesquisa do Google Acadêmico, visto que outras bases de pesquisas acadêmicas como Scientific Electronic Library Online e Web of Science, por exemplo, não apresentavam artigos científicos com o termo "jurimetria", destacando-se que somente na grafia em português. É importante que se reconheça que outras fontes como a Rede Virtual de Bibliotecas apresentaram artigos presentes na pesquisa realizada via Google Acadêmico. Sendo assim, sugerem-se estudos realizados em bases de teses e dissertações, que, de certa forma, apresentam pesquisas mais contemporâneas. Além disto, bases específicas que versam sobre Direito, como por exemplo, a Bibliografia 


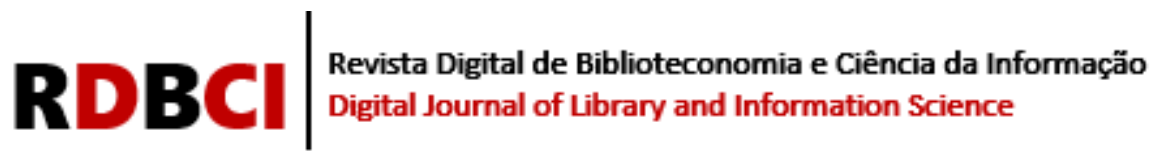

Brasileira de Direito (BBD) mantida perlo Senado Federal, devem ser levadas em consideração em pesquisas futuras.

Além disto, o estudo limitou-se a um aspecto exclusivamente descritivo. Há que aprofundar no contexto das citações, visto que, segundo Thomaz, Assad e Moreira (2011, p. 90),

O número de publicações, das citações e da média de citações por trabalho publicado, tomados isoladamente, são índices bibliométricos tradicionais que apresentam deficiências, pois não retratam a informação combinada dos trabalhos publicados com as respectivas citações.

Também se vislumbra a oportunidade de estudos bibliométricos comparativos, principalmente associados à análise de citações, entre a produção científica brasileira e estrangeira. Neste sentido, métodos como a mineração de textos podem proporcionar uma compreensão mais ampla dos estudos.

De qualquer maneira, a crítica quanto ao uso exclusivo de indicadores bibliométricos, vinda de pesquisadores como Ioannidis, et al., (2017), Hicks, et al., (2015) e, Stephan, Veugelers e Wang (2017), não desqualificam aplicações em um contexto no qual se estabelecem cenários capazes de lançar luz sobre um corpo de conhecimento - de relevante utilidade no desenvolvimento de novos estudos.

\section{REFERÊNCIAS}

AITCHISON, L.; CORRADI, N.; LATHAM, P. E. Zipf's Law arises naturally when there are underlying, unobserved variables. Plos, v. 12, n. 2, p. 1-32, dec. 2016.

ALVARADO, R. U. A lei de Lotka na bibliometria brasileira. Ciência da Informação, Brasília, v. 31, n. 2, p. 14-21, mai/ago 2002.

ANDRADE, M. D. A utilizacao do sistema R-Studio e da jurimetria como ferramentas complementares à pesquisa juridica. Revista Quaestio Iuris, Rio de Janeiro, v. 11, n. 2, p. 680-692, 2018.

ARAÚJO, C. A. Bibliometria: evolução histórica e questões atuais. Em Questão, Porto Alegre, v. 12, n. 1, p. 11-32, jan/jun 2006.

ARIA, M.; CUCCURULLO, C. Bibliometrix: an R-tool for comprehensive science mapping analysis. Journal of Informetrics, v. 11, n. 4, p. 959-975, november 2017.

ARIDA, P.; BACHA, E.; LARA-RESENDE, A. Credit, interest, and jurisdictional uncertainty: conjectures on the case of Brazil. In: GIAVAZZI, F.; GOLDFAJN, I.; HERRERA, S. Inflation Targeting, Debt, and the Brazilian Experience, 1999 to 2003. Cambridge: MIT Press, p. 265-293, 2005.

BASSI, M. C.P.C.; SCHUMAK, F. A busca pela eficiência judicial: uma análise epistemológica multidisciplinar. Caderno Programa de Apoio à Iniciação Científica, Curitiba, v. 19, n. 1, p. 719-736, 2018. 


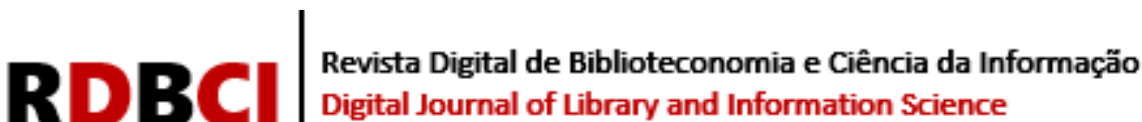

BERNOULLI, N. Dissertatio Inauguralis Mathematico-Juridica. Charleston: Nabu Press, 2012.

BERTRAN, M. P. Análise econômica como critério orientador de decisão judicial: aplicações e limites, estudo a partir do caso de revisão dos contratos de arrendamento mercantil com paridade cambial. 2006. 168 f. Dissertação (Mestrado em Direito) Universidade de São Paulo: São Paulo. 2006.

BISPO, M. V.L.; GONÇALVES, J. T. Jurimetria como gestão dos processos do Poder Judiciário. Revista de Estudos Jurídicos e Sociais, Cascavel, v. 1, n. 1, p. 55-67, dez. 2019.

BOOTH, A. D. A "Law" of occurrences for words of low frequency. Information and Control, v. 10, n. 4, p. 386-393, april 1967.

BORGES, P. C.R. Métodos quantitativos de apoio à bibliometria: a pesquisa operacional pode ser uma alternativa? Ciência da Informação, Brasília, v. 31, n. 3, p. 5-17, set/dez 2002.

BOYD, C. L.; EPSTEIN, L.; MARTIN, A. D. Untangling the causal effects of sex on judging. American Journal of Political Science, v. 54, n. 2, p. 389-411, april 2010.

BRADFORD, S. C. Sources of information on scientific subjects. Engineering, v. 26, p. 85-86, jan 1934.

BRITTO, L. M.T.; LACERDA, L. R.; KARNINKE, T. M. A crise do congestionamento do Poder Judiciário e a ingerência dos conflitos de massa no prejuízo doacesso à justiça. Seriam as técnicas coletivas de repercussão individual instrumentos necessários para desestimular a litigância habitual? In: CONGRESSO DE PROCESSO CIVIL INTERNACIONAL, 3, 2018, Vitória. Anais... Vitória: Universidade Federal do Espírito Santo.

CALlON, M.; COURTIAL, J. P.; PENAN, H. Cientometria: El Estudio Cuantitativo de la Actividad Científica: de la Bibliometría a la Vigilancia Tecnológica. Gijón: Ediciones Trea, 1995.

CÂNDIDO, R. B. et al. Lei de Lotka: um olhar sobre a produtividade dos autores na literatura brasileira de finanças. Encontros Bibli, Florianópolis, v. 23, n. 53, p. 1-15, set/dez 2018.

CASILLAS, C. J.; ENNS, P. K.; WOHLFARTH, P. C. How public opinion constrains the U.S. Supreme Court. American Journal of Political Science, v. 55, n. 1, p. 74-88, january 2011.

CHUEKE, G. V.; AMATUCCI, M. O que é bibliometria? Uma introdução ao Fórum. Revista Eletrônica de Negócios Internacionais, São Paulo, v. 10, n. 2, p. 1-5, mai./ago. 2015.

COUTO, M. B.; OLIVEIRA, S. P. Gestão da justiça e do conhecimento: a contribuição da jurimetria para a administração da justiça. Revista Jurídica, Curitiba, v. 2, n. 43, p. 771-801, 2016. 


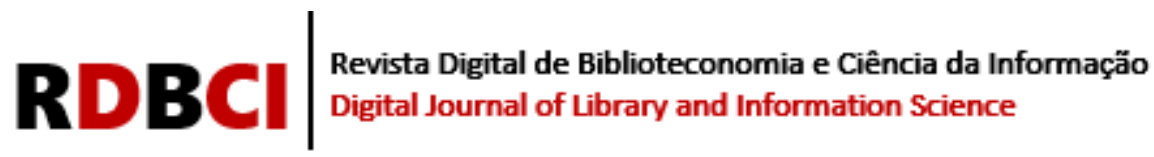

DELGADO, J. A. O direito informático. Genesis Revista de Direito do Trabalho, Curitiba, v. 22, n. 117, p. 388-390, set. 2002.

DUARTE, F. A.; NUNES, D. Jurimetria e tecnologia: diálogos essenciais com o direito processual. Revista de Processo, São Paulo, v. 45, n. 299, p. 405-448, jan. 2020.

EPSTEIN, L.; KOBYLKA, J. F. The Supreme Court and Legal Change: Abortion and the Death Penalty. Chapel Hill: The University of North Carolina Press, 1992.

EPSTEIN, L.; LANDES, W. M.; POSNER, R. A. The Behavior of Federal Judges: A Theoretical and Empirical Study of Rational Choice. Cambridge: Harvard University Press, 2013.

EPSTEIN, L.; MARTIN, A. D. Does public opinion influence the Supreme Court? Possibly yes (but we're not sure why). Journal of Constitutional Law, Philadelphia, v. 13, n. 263, p. 263-281, december 2010.

ESTOUP, J. B. Gammes Sténographiques. Paris: Hachette Livre, 2018.

FALAGAS, M. E. et al. Comparison of PubMed, Scopus, Web of Science, and Google Scholar: strengths and weaknesses. The FASEB Journal, Bethesda, v. 22, n. 2, p. 338-342, february 2008 .

FARHANG, S.; WAWRO, G. Institutional dynamics on the US Court of Appeals: minority representation under panel decision making. Journal of Law, Economics \& Organization, v. 20, n. 2, p. 299-330, 2004.

FAVARETTO, J. E.R.; FRANCISCO, E. R. Exploração do acervo da RAE - Revista de Administração de Empresas (de 1961 a 2016) à luz da bibliometria, text mining, rede social e geoanálise. Revista de Administração de Empresas, São Paulo, v. 57, n. 4, p. 365-390, jul/ago 2017.

FONSECA, E. N. Bibliometria: Teoria e Pratica. São Paulo: Cultrix, 1986.

GARFIELD, E. Citation indexes: new paths to scientific knowledge. The Chemical Bulletin, v. 3, n. 4, p. 11, 1956.

GARGANO, R. S.; NADER, C. C.F.C. As controvérsias acerca da aplicação da jurimetria da pena nas relações de consumo dos juizados especiais cíveis. Alumni, v. 6, n. 11, p. 18-31, $\mathrm{jul} / \mathrm{dez} 2018$.

GARGANO, R. S.; NADER, C. C.F.C. As controvérsias acerca da aplicação da Jurimetria da pena nas relações de consumo dos Juízados Especiais Cíveis. Alumni, Belford Roxo, v. 6, n. 12, p. 17-31, jul./dez. 2018. 


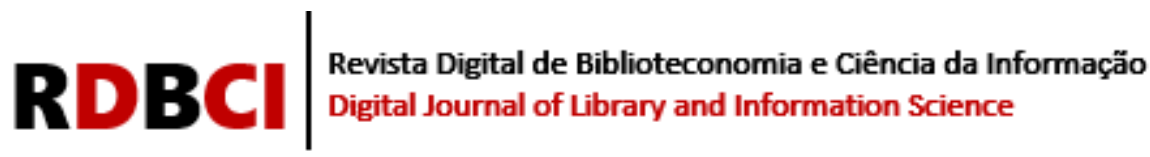

GILES, M. W.; BLACKSTONE, B.; VINING JR, R. L. The Supreme Court in american democracy: unraveling the linkages between public opinion and judicial decision making. The Journal of Politics, Chicago, v. 70, n. 2, p. 293-306, april 2008.

GINGRAS, Y. Os Desvios da Avaliação da Pesquisa: o Bom Uso da Bibliometria. Rio de Janeiro: UFRJ, 2016.

GUEDES, V. L.S. Estudo de um critério para indexação automática derivativa de textos científicos e tecnológicos. Ciência da Informação, Brasília, v. 23, n. 3, p. 318-326, set/dez 1994.

HALD, A. A History of Statistics and Probability and Their Application Before 1750. New Jersey: John Wiley \& Sons, 2003.

HARZING, A. W.; ALAKANGAS, S. Google Scholar, Scopus and the Web of Science: a longitudinal and cross-disciplinary comparison. Scientometrics, v. 106, n. 2, p. 787-804, february 2016.

HICKS, D. et al. Bibliometrics: the Leiden Manifesto for research metrics. Nature, v. 520, n. 7548, p. 429-431, april 2015.

HIRSCH, J. E. An index to quantify an individual's scientific research output. Proceedings of the National academy of Sciences, v. 102, n. 46, p. 16569-16572, 2005.

HOLMES JR, O. W. The Path of the Law. Cambridge: Harvard Law Review, 1897.

IOANNIDIS, J. P.A. et al. Bibliometrics: is your most cited work your best? Nature, v. 514, n. 7524, p. 561-562, october 2017.

KING, K. L.; GREENING, M. Gender justice or just gender? The role of gender in sexual assault decisions at the International Criminal Tribunal for the former Yugoslavia. Social Science Quarterly, v. 88, n. 5, p. 1049-1071, december 2007.

LOEVINGER, L. Jurimetrics: the methodology of legal inquiry. Law and Contemporary Problems, v. 28, n. 1/2, p. 5-35, winter 1963.

LOEVINGER, L. Jurimetrics: the next step forward. Jurimetrics Journal, v. 12, n. 1, p. 3-41, september 1971.

LOPES, F. M.; AZEVEDO, P. F. Government appointment discretion and judicial independence: preference and opportunistic effects on Brazilian Courts. Economic Analysis of Law Review, Brasília, v. 9, n. 2, p. 84-106, mai/ago 2018.

LOTKA, A. J. The frequency distribution of scientific productivity. Journal of the Washington Academy of Sciences, v. 16, n. 12, p. 317-323, june 1926. 


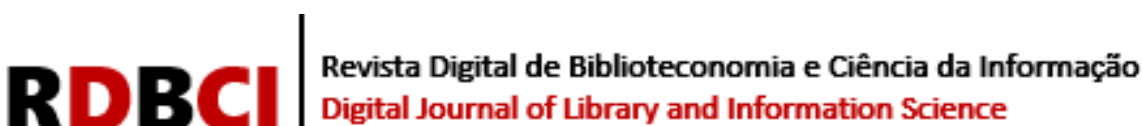

LUVIZOTTO, J. C.; GARCIA, G. P. A jurimetria e sua aplicação nos tribunais de contas: análise de estudo sobre o Tribunal de Contas da União (TCU). Revista Controle - Doutrina e Artigos, Fortaleza, v. 18, n. 1, p. 46-73, jan./jun. 2020.

MACHADO, M. R. Pesquisar Empiricamente o Direito. São Paulo: Rede de Estudos Empíricos em Direito, 2017.

MACHADO, U. A.L. A convergência entre o privilégio de exploração da criação intelectual e a elaboração de um direito do espaço virtual com suas consequiências sobre o domínio público. 2003, 348 f. Dissertação (Mestrado em Direito) - Universidade Federal de Pernambuco: Recife. 2003.

MANIN, D. Y. Zipf's Law and avoidance of excessive synonymy. Cognitive Science, Medford, v. 32, n. 7, p. 1075-1098, oct./nov 2008.

MELLO, P. M.A.C. Interdisciplinaridade na Pós-Graduação: estudo de seu impacto na produção de teses e dissertações do Programa de Pós-Graduação em História das Ciências e das Técnicas e Epistemologia da Universidade Federal do Rio de Janeiro. Tese (Doutorado em História das Ciências e das Técnicas e Epistemologia), Universidade Federal do Rio de Janeiro: Rio de Janeiro, RJ, Brasil, 2017.

MENEZES, D. F.N.; BARROS, G. P. Breve análise sobre a Jurimetria, os desafios para a sua implementação e as vantagens correspondentes. Duc In Altum, v. 9, n. 19, p. 45-83, set/dez 2017.

MINGERS, J.; LEYDESDORFF, L. A review of theory and practice in scientometrics. European Journal of Operational Research, v. 246, p. 1-19, 2015.

MORAES, M.; FURTADO, R. L.; TOMAÉL, M. I. Redes de citação: estudo de rede de pesquisadores a partir da competência em informação. Em Questão, Porto Alegre, v. 21, n. 2, p. 181-202, mai/ago 2015 .

MORETTI, S. L.A.; CAMPANARIO, M. A. A produção intelectual brasileira em Responsabilidade Social Empresarial - RSE sob a ótica da bibliometria. Revista de Administração Contemporânea, Curitiba, v. 13, n. especial, p. 68-86, junho 2009.

NICHOLLS, P. T. Empirical validation of Lotka's law. Information Processing \& Management, v. 22, n. 5, p. 417-419, 1986.

NUNES, M. G. Jurimetria: como a estatística pode reinventar o Direito. São Paulo: Revista dos Tribunais, 2016.

OLIVEIRA, A. A.S.; LIMA, C. G.S.; MORAIS, K. K.C. Bibliometria e metassíntese de estudos sobre trabalhos publicados na revista Psicologia \& Sociedade. Psicologia \& Sociedade, Belo Horizonte, v. 28, n. 3, p. 572-581, dezembro 2016. 


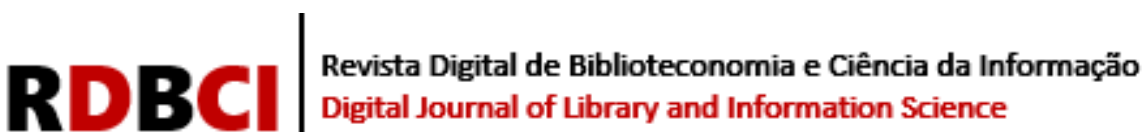

OTLET, P. Traité de Documentation: Le Livre Sur Le Livre, Theorie et Pratique. Bruxelles: Mundaneum, 1934.

PAO, M. L. Automatic text analysis based on transiction phenomena of word. Journal of the American Society for Information Science, v. 29, n. 3, p. 121-124, may 1978.

PAO, M. L. Lotka's law: A testing procedure. Information Processing \& Management, v. 21, n. 4, p. 305-320, 1985.

PERESIE, J. L. Female judges matter: gender and collegial decisionmaking in the federal appellate courts. The Yale Law Journal, New Haven, v. 114, n. 7, p. 1759-1790, may 2005.

PIMENTEL, A. F. Principiologia juscibernética. Processo telemático. Uma nova teoria geral do processo e do direito processual civil. 2003. 966 f. Tese (Doutorado em Direito) Universidade Federal de Pernambuco: Recife, p. 966. 2003.

PINTADOSI, S. T. Zipf's word frequency law in natural language: a critical review and future directions. Psychonomic Bulletin \& Review, Chicago, v. 21, n. 5, p. 1112-1130, oct. 2014.

PONCZEK, V.; GREZZANA, S. Gender bias at the Brazilian Superior Labor Court. Brazilian Review of Econometrics, Rio de Janeiro, v. 32, n. 1, p. 73-96, 2012.

PRITCHARD, A. Statistical bibliography or bibliometrics. Journal of Documentation, v. 25, n. 4, p. 348-349, december 1969.

PRITCHETT, C. H. Public law and judicial behavior. The Journal of Politics, Chicago, v. 30, n. 2, p. 480-509, may 1968.

QUONIAM, L. et al. Inteligência obtida pela aplicação de data mining em base de teses francesas sobre o Brasil. Ciência da Informação, Brasília, v. 30, n. 2, p. 20-28, mai/ago 2001.

RANGEL, R. C. A jurimetria aplicada ao direito das familias. Revista Sintese: Direito de Familia, Sao Paulo, v. 15, n. 86, p. 99-111, out/nov 2014.

SANTOS, G. C. Análise bibliométrica dos artigos publicados como estudos bibliométricos na história do Congresso Brasileiro de Custos. Pensar Contábil, Rio de Janeiro, v. 17, n. 62, p. 4-13, 2015.

SILVA, A. P.F. et al. Estudo bibliométrico sobre custo em organizações da construção civil: contribuições do congresso brasileiro de custo de 1996 a 2010. In: CONGRESSO

BRASILEIRO DE CUSTOS, 19, 2012, Bento Gonçalves. Anais... São Leopoldo: Associação Brasileira de Custos.

SILVA, E. L.S.; MENEZES, E. M. Metodologia da Pesquisa e Elaboração de Dissertação. 4. ed. Florianópolis: UFSC, 2005. 


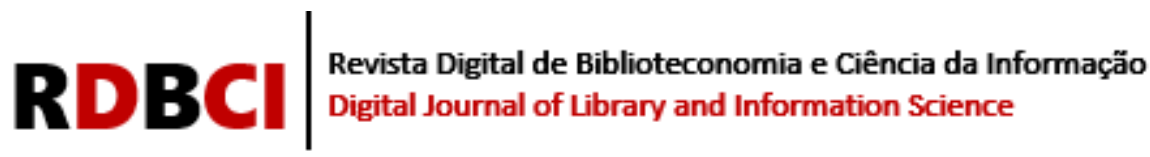

SILVA, M. R.; HAYASHI, C. R.M.; HAYASHI, M. C.P.I. Análise bibliométrica e cientométrica: desafios para especialistas que atuam no campo. Revista de Ciência da Informação e Documentação, São Paulo, v. 2, n. 1, p. 110-129, jan./jun. 2011.

SMYTH, R. The role of attitudinal, institutional and environmental factors in explaining variations in the dissent rate on the High Court of Australia. Australian Journal of Political Science, v. 40, n. 4, p. 519-540, december 2005.

STEPHAN, P.; VEUGELERS, R.; WANG, J. Reviewers are blinkered by bibliometrics. Nature, v. 544, n. 7651, p. 411-412, april 2017.

THOMAZ, P. G.; ASSAD, R. S.; MOREIRA, L. F.P. Uso do fator de impacto e do índice H para avaliar pesquisadores e publicações. Arquivos Brasileiros de Cardiologia, São Paulo, v. 96, n. 2, p. 90-93, fevereiro 2011.

VANTI, N. A.P. Da bibliometria à webometria: uma exploração conceitual dos mecanismos utilizados para medir o registro da informação e a difusão do conhecimento. Ciência da Informação, Brasília, v. 31, n. 2, p. 152-162, 2002.

VANZ, S. A.D.S.; CAREGNATO, S. E. Estudos de citação: uma ferramenta para entender a comunicação científica. Em Questão, Porto Alegre, v. 9, n. 2, p. 295-307, jul/dez 2003.

VASCONCELOS, F. A. Responsabilidade do provedor pelos danos praticados na Internet. 2002. 279 f. Tese (Doutorado em Direito) - Universidade Federal de Pernambuco: Recife. 2002.

VENTURINI, L. D.B.; SOUZA, A. R.L.D.; BIANCHI, M. Eficiência na alocação dos recursos públicos do Poder Judiciário: um estudo na $4{ }^{\text {a }}$ Região Federal. In: CONGRESSO BRASILEIRO DE CUSTOS, 25, 2018, Vitória. Anais... Vitória: Universidade Federal do Espírito Santo.

YEUNG, L. Jurimetria ou Análise Quantitativa de Decisões Judiciais. In: MACHADO, M. R.). Pesquisar Empiricamente o Direito. São Paulo: Rede de Estudos Empíricos em Direito, p. 428, 2017. Cap. 8.

YEUNG, L. L.T.; AZEVEDO, P. F.A. Nem Robin Hood, nem King John: testando o viés anti-credor e anti-devedor dos magistrados brasileiros. Economic Analysis of Law Review, Brasília, v. 6, n. 1, p. 1-22, jan/jun 2015.

YOSHIDA, N. D. Análise bibliométrica: um estudo aplicado à previsão tecnológica. Future Studies Research Journal, São Paulo, v. 2, n. 1, p. 55-84, jan./jun. 2010.

ZABALA, F. J.; SILVEIRA, F. F. Jurimetria: estatistica aplicada ao Direito. Revista Direito e Liberdade, v. 16, n. 1, p. 87-103, 2014.

ZIPF, G. K. Human Behavior and the Principle of Least Effort. Eastford: Martino Fine Books, 2012. 




Artigo submetido ao sistema de similaridade 